\title{
Tissue Engineering of Organs: Brain Tissues
}

\author{
Deniece Fon, David R. Nisbet, George A. Thouas,
}

Wei Shen, and John S. Forsythe

\subsection{Introduction}

Anatomical organization and precise interconnectivity of neurons in the adult brain are critical for correct physiological function and integration of cognitive, sensory, and motor control. Individual neurons, the functional signaling units of the brain, are essentially highly integrated signal transducers. Inputs in the form of membrane potentials travel uni-directionally to the cell body of the neuron via membranous branches called dendrites, and then proceed down a larger elongated process, the axon, to join at closely apposed membrane junctions (synapses) with neighboring neuronal cell bodies. The highly precise spatial patterning of neuronal connections established during early brain development is the result of an orchestrated series of programmed differentiation events, regulated by controlled cell proliferation, migration, and differential adhesion. In particular, the establishment of connectivity relies heavily on the guidance of axons from their points of origin to their appropriate targets, over variable distances and in a precise spatial manner. This process is regulated by a host of environmental cues

\footnotetext{
D. Fon $(\bowtie)$, D.R. Nisbet, and J.S. Forsythe

Department of Materials Engineering, Monash University,

Clayton, VIC 3800, Australia

e-mail: deniece.fon@eng.monash.edu.au
}

G.A. Thouas

Division of Biological Engineering, Monash University, Clayton, VIC 3800, Australia and

Department of Zoology, The University of Melbourne,

Melbourne, VIC 3000, Australia

\section{W. Shen}

Australian Pulp and Paper Institute, Department of Chemical Engineering, Monash University

Clayton, VIC 3800, Australia presented to the growth cone, a specialized ending at the tip of immature neurons, in specific spatial and temporal sequences. The spatial location of neurons, their relationship to other neurons, and the threedimensional (3D) distribution of their axons within the nervous system are all crucial for normal brain function. The sheer complexity of adult brain anatomy and physiology, the adaptive and dynamic nature of the tissue, and the fact that many aspects of function are still being defined biologically, present major challenges for brain tissue engineering (BTE) and regeneration approaches.

The regenerative capacity of neurons in the brain following disease and injury is very limited and as a result, therapy is largely limited to rehabilitative measures at the level of behavioral entrainment of the patient. This limited regenerative capacity is due to the gradual loss of the intrinsic ability within the extracellular environment to promote cell division, axon outgrowth, and major structural remodeling at the tissue level, at the completion of corticogenesis (toward the end of fetal and neonatal development) [95]. There is, however, residual neuronal adaptability or "plasticity" in the adult brain that is modulated at the level of individual cells and synapses, which is evident in cases of enhanced and relocated cognitive function in patients following severe brain lesions [136]. Like all tissues, the central nervous system (CNS) also undergoes a staged inflammatory response following mechanical insults (e.g., compression or tearing) or other damage (e.g., ischemia or embolism). In the short term, localized fluid accumulation and leukocyte infiltration contribute to the formation of a cytotoxic environment at the injury site. In the longer term, the wound site is usually replaced by glial scarring, in the form of fibrotic tissue. Thus, in addition to the limited regenerative capacity, biochemical and biomechanical 
immunogenic factors at the injury site can act in unison to dramatically inhibit axon regrowth [70, 132].

Tissue engineering can be considered to be an application of engineering disciplines dedicated to the development of solutions, based on an understanding of biological systems, for the repair and restoration of dysfunctional tissue. Typically, solutions are envisaged as variable combinations of the following components: cells, scaffolds, and biomolecules. The optimal combinatorial treatment is dependent on the cell and tissue structures affected. In the context of brain repair, drug therapy represents a complex challenge in terms of demonstrating neuroprotective benefits, such as the modulation of the innate immune response [105]. In addition, the biological causes of many neurodegenerative brain conditions remain largely undefined. For these reasons, the topic of pharmacological induction of neuronal protection and/or regeneration will not be explored in depth in this chapter. Regardless of the cause of injury, under certain situations, the simple replacement of cells or scaffolds alone may provide a tissue engineering repair strategy that is sufficient to restore tissue function. Cell replacement therapies are particularly useful in this way, in particular for disorders that result in multifocal lesions such as multiple sclerosis (MS), where centrally administered cells can be targeted to focal sites of degeneration to promote repair. To these ends, there have been extensive studies into the efficacy of embryonic and adult stem cells as deliverable neural progenitor cells (NPCs) in experimental models, and more recently in clinical trials [8, 41, 57]. Similarly, scaffold biomaterials are also emerging as having therapeutically relevant uses in brain repair, although their clinical applications have not yet been fully realized. It is plausible that an optimized combination of stem cells and biomimetic scaffolds can further enable the bypassing of formidable barriers such as cytotoxic immunogenic microenvironments or local scar regions. This chapter will focus on the design, fabrication, and biofunctionalization of scaffolds to enable neuronal repair in the diseased or injured brain, in particular at focal injury sites. Some consideration of combinatorial approaches will also be made in due course.

The ultimate goal of BTE is to restore tissue structure and function to its original state. Loss of brain function often reflects the loss of connectivity between specific tracts or centers; hence, the main emphasis is on encouraging directed axonal regrowth. Recent efforts aimed at regenerating axons have exploited stem cells to recapitulate the events of embryonic development that promote axon extension and guided outgrowth to appropriate targets, and to eventually reinstate the reformation of neuronal connections in the mature brain tissue. During development, this is a complex physicochemical interplay between cell populations and their extracellular microenvironment in a 3D orientation. In this regard, BTE often involves the synthesis of implantable, 3D porous biomaterial scaffolds that act as supportive cellular microenvironments, a feature that is becoming increasingly important in terms of mature brain function, and induction of local tissue repair.

The concept of the cellular microenvironment (or niche) is central to BTE scaffold design, particularly in relation to biological aspects of neuronal regeneration in situ, where there exist overlaps with aspects of stem cell biology and specific cell-cell and cell-substrate interactions. There are intrinsic differences between the structure and function of the embryonic and adult brain that need to be considered; while the embryonic brain is involved in the establishment of neuronal networks, axonal fasciculation, and myelination, the adult brain is often engaged in a process of neuronal plasticity, conserved fasciculation, and maintenance of consolidated synapses without anatomical reorganization. As a consequence, compared to embryonic development, regeneration in an adult brain requires axons to traverse longer distances in order to reform connections within established neuronal pathways. In addition to intrinsic differences between the adult and embryonic brain, there are distinct differences within the different extracellular environments and their response to injury, such as the formation of physical scars and the local release of inhibitory factors by microglia and reactive astrocytes [51]. The multitude of guidance cues responsible for sculpting the neural connections of the brain are downregulated upon completion of development, but can still persist within the mature CNS to preserve the intricate neuronal circuitry by exerting inhibitory influences on axon outgrowth [159]. For example, certain signaling molecules, such as myelin-associated glycoprotein (MAG) can have variable effects on neurite outgrowth, transitioning from a promoter to an inhibitor of neurite outgrowth at birth $[33,69,159]$. Therefore, while it is important to fabricate niche microenvironments that encourage neuronal differentiation and guided neurite outgrowth, neuronal regeneration in an adult brain may not necessarily require identical conditions to those present during development. Regardless of the precise biological mechanisms involved at the 
cellular level, BTE scaffolds represent the most adaptable materials engineering strategy for clinically relevant brain tissue repair due to their control of cell-biomaterial interactions, matching of structural and physical properties, and the provision of microenvironments at the cellular scale, as discussed in further detail in the following sections.

\subsection{Aim of the Discipline}

Disease and injury occurring in the brain often result in significant disruption of the normal physiological structure and function, with common occurrences of neuron death and/or demyelination. Loss of brain function often reflects the loss of connectivity between specific neuronal populations; hence, a key hypothesis in BTE is that entrainment of axonal guidance to designated targets can lead to restored function. Because of the multiple cell types involved in disease and injury, there is no single strategy to achieve this. However, common to many BTE strategies is the fabrication of synthetic cellular micro-environments, which consist of critical features to promote tissue regeneration by assisting combinations of cell proliferation, neuronal migration, and differentiation. Remnants of the permissive and instructive environment present during development persists within the adult brain, but are confined to distinct anatomical regions in the form of stem cell niches. Under certain injury conditions, endogenous neuronal stem cells (NSCs) in adult mammalian brains have been shown to imitate embryonic development to achieve regeneration $[4,20,45,46,96,148]$. Thus, most approaches are on the basis of the belief that the molecular pathways responsible for directing appropriate cellular behavior during embryonic development are conserved in the adult brain, and participate in the process of regeneration. However, the confinement of neurogenesis to highly compartmentalized locations in the brain suggests that an additional role of the stem cell niche is to shield ongoing neurogenesis from inhibitory influences that naturally occur within the brain. Therefore, an additional unique complement of regulatory mechanisms must also be present for neurogenesis to proceed in the adult brain [118].

When exposed to the appropriate conditions, stem cells can be coaxed into committing to different cell lineages, producing specific cell types (e.g., neurogenesis and gliogenesis) that may be required for different BTE strategies. This is important because brain tissue consists of many cell types, including neurons, astrocytes, microglia, and oligodendrocytes; so tissue repair will also require the use of multiple cell types. Stem cell function is largely dependent on the niche conditions in which they exist. As the natural stem cell niche is a dynamic environment that is subject to alteration by external influences, this provides a gateway for intervention in stem cell behavior by engineering a synthetic niche bearing the critical properties required for tissue remodeling.

\subsubsection{The Neuronal Niche}

It has long been established that stem cells exist in niches, which are specialized microenvironments capable of maintaining the immature state of stem cell populations, in terms of self-renewal and multipotency, as well as partially dictating its differentiation pathway $[109,118,126]$. A stem cell niche is a dynamic environment that provides structural support, architectural features, and a range of support cells and signaling molecules, which are all instructive for directing stem cell behavior in response to the state of the tissue. The presence of NSCs within discrete locations of the adult brain is highly relevant to the development of therapeutic brain repair strategies, whether it is through stimulation of the endogenous populations, or by transplantation into affected areas. Both approaches require comprehensive understanding of how regulation of stem cell behavior is achieved normally in vivo. Adult NPCs have been isolated in two distinct regions of the human brain - the subventricular zone (SVZ) and subgranular zone (SGZ); these regions have been extensively studied to identify the critical components that define its unique ability to foster the maintenance, growth, and development of stem cells [3, 37, 97, 118, 126]. While much progress has been made in identifying individual components that form these niches, future success in recreating a synthetic niche environment will require a comprehensive understanding of their histological and extracellular composition, and how the different components interact and converge to give rise to precise control of stem cell behavior.

Physical, structural, and architectural cues within stem cell niches exist in the form of a specialized basal lamina (enabling cell anchorage) and various extracellular matrix (ECM) components that modulate the availability of cell signaling molecules by sequestering 
relevant growth factors and cytokines [118]. Different types of support cells exist within the niche (e.g., astrocytes, ependymal cells, and endothelial cells), which generally function to integrate signals from within the niche environment, and influence resident stem cell behavior via the secretion of paracrine factors or contactmediated cues accordingly. These signals are influenced locally by neurotransmitters secreted from synaptic junctions, and long-distance signalling from hormones and cytokines in the blood stream. Locally, niches can also be influenced by trophic factors, mitogens, and morphogens - secreted from neighboring populations of support cells and differentiated cells, which form part of a complex feedback mechanism $[109,118,126]$. The general view is that an acute release of factors from injury sites can induce differentiation in these niches, providing new differentiated cells for repair.

\subsubsection{Engineering Cellular Microenvironments}

The basis of most tissue engineering strategies is to first engineer a biomimetic of the extracellular microenvironment with favorable architecture to encourage cell adhesion and survival. The native extracellular microenvironment consists of a myriad of biomolecular factors that can affect cellular processes in vivo; these can be classified broadly into three main components [85]:

1. Insoluble hydrated macromolecules

- Fibrillar proteins (e.g., collagens)

- Noncollagenous glycoproteins (e.g., elastin, laminin, fibronectin)

- Hydrophilic proteoglycans with large glycosaminoglycan side chains

2. Soluble macromolecules

- Growth factors

- Chemokines

- Cytokines

- Peptides

3. Cell-surface glycoproteins

- Growth factor receptors

- ECM receptors

The molecular structures that make up the cellular microenvironment (including the ECM) represent a complex array of signals manufactured by cells, to which they respond in a temporally and spatially coordinated manner. Ultimately, the highly organized nature of cell populations is critical in complex tissue dynamics such as tissue formation, homeostasis, and regeneration [85].

Scaffolds can be engineered to impart a range of biochemical and biomechanical cues that can be presented as signaling entities that guide neurite outgrowth. Such cues interact with the growth cone of a neurite and can act to either attract or repel outgrowth, enabling a growing axon to navigate through neighboring microenvironments toward specific targets [5]. Much progress is being made in understanding the roles of specific cues within the extracellular microenvironment, and how these cues can be translated and used in combination to have synergistic and hierarchical effects on specific cellular processes that directly affect the regeneration of brain tissue.

Physical cues can be incorporated into a scaffold by controlling the morphology and surface topography during fabrication. Aligned features, acting as conduits, can be in the form of electrospun polymer nanofibers or regular patterns of surface-etched grooves and ridges on planar surfaces, all of which can direct neurite outgrowth by a process known as contact guidance $[73,116,142,158]$. The dimensions of such features are often at the micro/nano-scale, mimicking the structure of native tissue. Substrate stiffness is another relevant physical cue that is known to affect neuronal development by coaxing stem cells down a particular lineage [41], as well as influencing the extent of neurite outgrowth in cells that have committed to the neuronal lineage $[6,43,67,78,151]$. In addition, matching mechanical properties between the scaffold and the native brain tissue will play a role in controlling inflammation, which will facilitate scaffold integration. Therefore, during scaffold design, considerations must be made to ensure that scaffold properties (e.g., elastic modulus and rheological properties) are similar to those of the native brain.

There have been many attempts to measure the viscoelastic properties of the brain. However, reported values in the literature often have large variations, which can be attributed to inherent biological variability in tissue properties (e.g., age, sex, species, region of brain tested, etc.), and more critically on the measurement protocol (e.g., methodology and apparatus used) [22]. While in vitro testing presents a simple and practical way of measuring physical properties of the brain, 
its accuracy in comparison to the properties of the brain in its natural state is questionable due to differences in hydration, blood perfusion, temperature regulation, postmortem tissue degeneration, and sample preparation artifacts [22]. In vivo testing is practically more difficult, and often ethically impossible in human subjects. Recent advances in magnetic resonance elastography (MRE) have made in vivo testing of viscoelastic properties in human and animal brains possible. However, its accuracy is limited because of attenuation of the propagating waves by tissue viscoelasticity, and variations in tissue stiffness within the intact structure. Nevertheless, the reported storage and loss moduli of human brain tissue, based on MRE, are in the range 1-12 $\mathrm{kPa}$ and $1-6 \mathrm{kPa}$, respectively [22, $53,54,149]$. Because of the brain's neuroarchitecture, it is expected that regional differences in the physical properties and a certain degree of anisotropy will exist. In addition, the bulk physical properties of the brain are influenced by factors such as hydration and intracranial pressure; hence, the relevance of these measured quantities to tissue engineering at the micro- and nanoscale is yet to be determined.

The effectiveness of biochemical cues in facilitating neuronal regeneration depends on the type of molecule and the method of incorporation, as these will influence the molecule's orientation and presentation to cells, and hence its bioactivity. Many proteins can have multiple binding motifs within the same molecule (e.g., RGD, IKVAV, and YIGSR within laminin), each of which can exhibit specific bioactivities. The stability of attachment will also determine whether presentation of the biomolecule is sustained (e.g., covalent attachment) or time-dependent (e.g., soluble, where the biomolecule can eventually be internalized by cells or diffuse away). Patterning of substrates with chemical moieties can be used as an additional means of controlling cell behavior. "Stamping" of substrates to create tracks or grids of specific biomolecules has been used to define the spatial location of a population of cells $[17,56,121,122]$. Neurites from dorsal root ganglia (DRG) cultured on $25 \mu \mathrm{m}$ wide tracks of vitronectin align with the direction of the adhesive tracks after $24 \mathrm{~h}$ of culture [17]. Similarly, NSCs cultured on an interconnected array of poly-L-lysine (PLL) square patches (with area in the order of $10^{4} \mu \mathrm{m}^{2}$, connected by lines $100-400 \mu \mathrm{m}$ long and $15 \mu \mathrm{m}$ wide) extend cellular protrusions along the interconnecting lines toward adjacent squares (Fig. 22.1) [121, 122].
Orientation of neurites on such patterned features is likely to reflect spatial confinement to regions of the substrate where outgrowth is favorable. This is supported by the observation that neurites growing outside of substrates patterned with protein retract back to their cell bodies [122]. Biomolecular patterns can also be deposited in the form of a static density gradient, which can potentially guide axon outgrowth along the gradient [71, 93]. This mechanism is known as chemotaxis, and is important for neurite guidance during development of the brain [36, 62, 134, 141].

An understanding of cell-scaffold interactions is also critical for the design of BTE scaffolds, particularly if a cell-based therapy is involved. One of the advantages of scaffolds is their ability to entrain threedimensionality, which can simulate tissue structure outside the physiological environment, a capability that even optimized in vitro tissue models fail to achieve. Scaffolds generally provide a relatively stable and potentially more representative physiological environment supporting cell outgrowth, enhancing cell survival and maintaining pluripotent populations as an artificial niche microenvironment.

Current research has been directed toward understanding the mechanisms by which cells interpret such cues, and the optimization of individual cues required to direct neurite outgrowth. While the presentation of individual cues to growing neurites in vitro has shown great promise in guiding neurite outgrowth, their effectiveness in vivo remains a major challenge. It is expected that within the complex and dynamic physiological environment, the ability of individual cues to guide neurite outgrowth may be limited. Therefore, studying the use of a combination of cues within a scaffold, which can potentially act synergistically to guide neurite extension, will become an important step toward achieving neuronal regeneration in vivo. This is a promising approach as structures at different length scales can also be incorporated to control different aspects of cell behavior. While the guidance of neurites to appropriate targets will ensure that signal outputs from regenerated cells are directed toward the right area, signal transmission between cells will depend on the correct formation of synapses (point of functional contact) at the designated target. Similarly, neurons need to receive input from the "right" type of cells, i.e., dendritic processes must also have appropriate connections. The ability to control neuronal positioning will also play an important role in reforming 


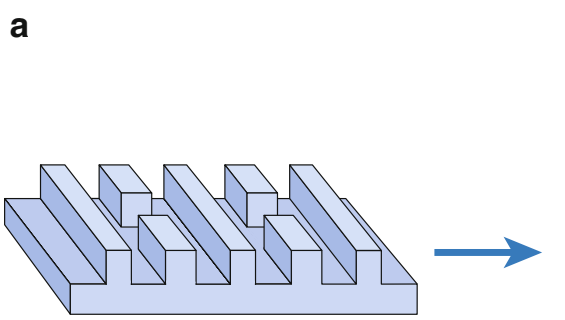

Si Master
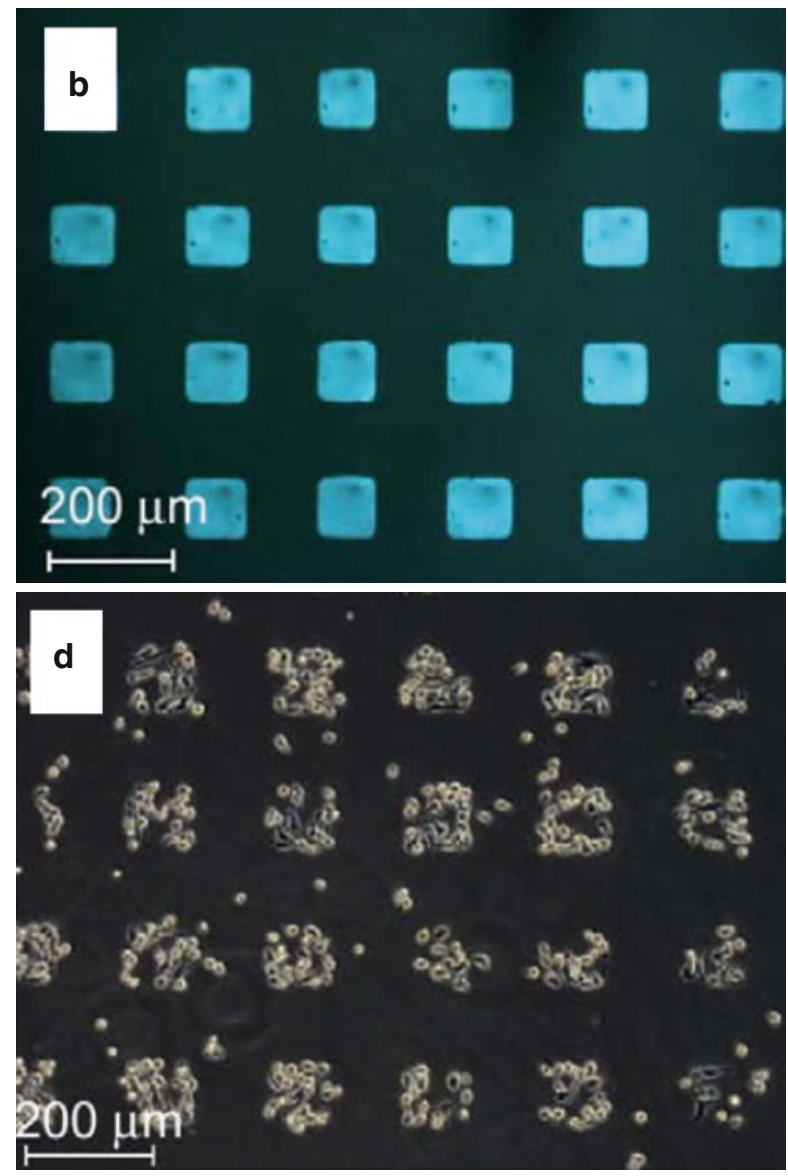

Fig. 22.1 (a) Schematic diagram illustrating the process of generating micropatterns by microcontact printing. (b, c) Fluorescence images of poly-L-lysine (PLL) patterns (light) microstamped onto PEO substrates (dark). (d, e) Fluorescence images of human umbilical cord blood neural stem cells (HUBC-

appropriate connections. Axon regenerations arising as a result of implants in the peripheral nervous system (PNS) have been shown to be capable of forming functional synapses at their designated targets, where electrical stimulation can trigger the release of neurotransmitters from axon terminals [73]. Despite differences between the CNS and PNS, neuronal circuits
PDMS

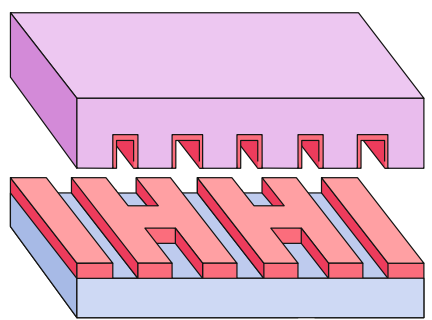

Substrate
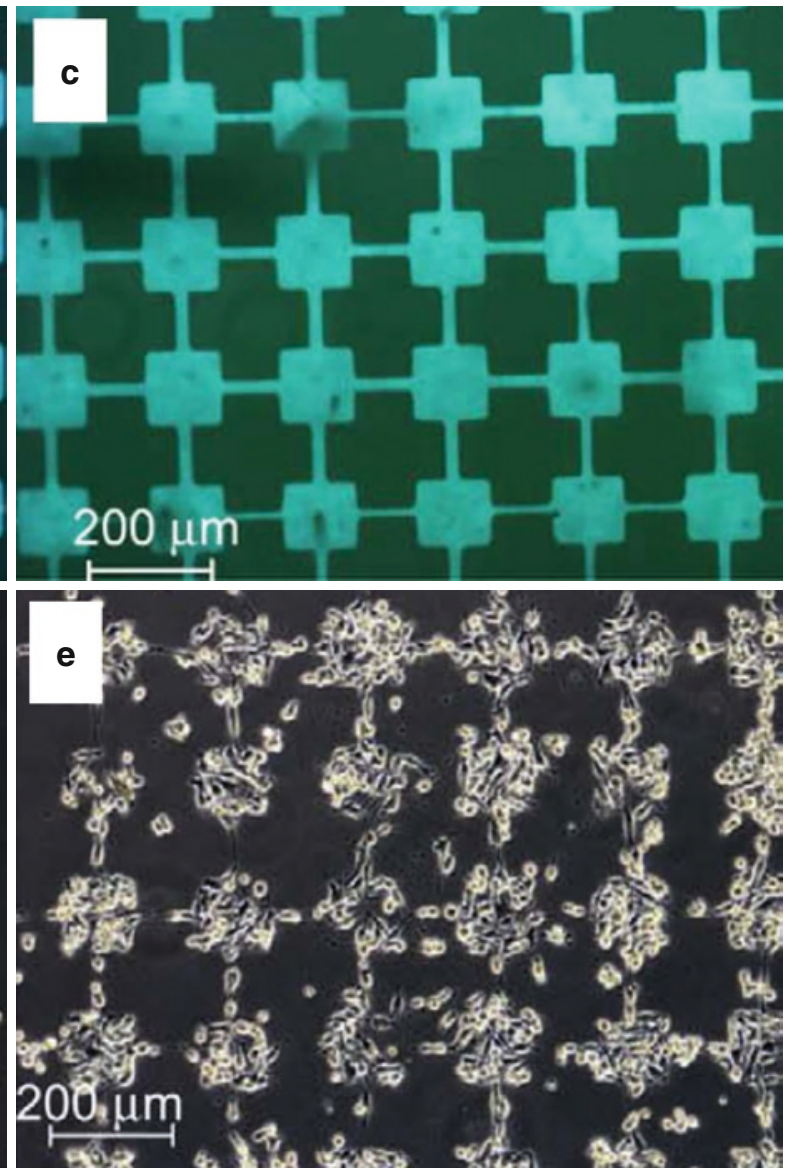

NSCs) cultured on PLL-patterned regions (corresponding to (b) and (c)) of PEO substrate. (a) Reproduced from Journal of Biomaterials Science, Polymer Edition, with permission of Brill. (b-e) reprinted from ref. [122]. Copyright (2008), with permission from Elsevier

in the adult brain remain partially plastic (where neuronal connections are amenable to a certain degree of modulation), and continually refined throughout life, a property that enables learning [70]. Therefore, the potential for refinement of nascent synapses appears possible through rehabilitation. Despite the many challenges that still exist in the field of tissue engineering, 
the foundations appear to be in place for functional recovery in the brain to be achievable.

\subsection{State of the Art}

As mentioned earlier, along the lines of the three wellestablished axioms of tissue engineering, it is envisaged that BTE strategies will consist of the following:

1. Cells

- Exogenous neuronal progenitor cells that replenish specific cell types lost due to disease or injury through regeneration and proliferation

- Other cell types, such as glia, may also be required to act as biological support that is representative of native niche microenvironments in the brain

\section{Scaffolds}

- Biocompatible materials with appropriate morphology and surface chemistry to ensure cell survival (i.e., by shielding cells from inhibitory environment within the injured brain) promote cell growth, and help direct certain aspects of cellular development

\section{Biological signaling}

- Biofunctionalization of biomaterial surfaces to encourage tissue integration in vivo

- Use relevant biological signals to mimic in situ conditions, eliciting specific cellular responses that are critical during regeneration

On the basis of these requirements, each of these components will be described in greater detail below.

\subsubsection{Exogenous Cell Source}

Exogenous cells are required as a source of cell replacement, and stem cells are often the primary choice because they present a renewable source of multipotent cells. While embryonic stem cells (ESCs) can be a possible exogenous source, their use in cell-based therapies is currently limited by feeder-dependent growth (expansion), immunosuppression, and their propensity to form teratomas in vivo [12, 108, 135]. On the other hand, adult (somatic) stem cells present a ready-to-use cell source, which have not yet been associated with tumor formation or toxic side effects when used in experimental and clinical settings in vivo settings [108]. The mechanism by which various transplanted somatic stem cells (e.g., hematopoietic stem cells or HSCs, mesenchymal stem cells or MSCs) promote neuronal repair has been attributed to not only their ability to act as a source of cell replacement, but also their ability to constitutively secrete neuroprotective and immunomodulatory molecules, which can preserve surviving cells [108].

Following disease or injury in the adult brain, successful repair and regeneration requires the expansion of a quiescent stem cell population, cell migration to the lesion site, differentiation into appropriate phenotypes, and integration into existing neuronal circuitry. It is acknowledged that sensitivity to signaling molecules and the subsequent cellular response will vary depending on the progress of a cell developmental program; therefore, it is accepted that optimal cellular response can only be obtained when a spectrum of biochemical and biophysical cues are presented to them in a temporally and spatially coordinated manner. The type of cells used in BTE applications will ultimately affect the scaffold properties and biological signaling required. As individual stem cell niche components are better understood we believe that the incorporation of support cells within scaffolds will be of equal importance in neural tissue regeneration applications.

In the same way that specialized support cells are present in the stem cell niche to help sustain stem cell function, incorporation of support cells in synthetic scaffolds are also required to facilitate the regeneration process. While it is envisioned that exogenous stem cells will promote regeneration by replacement of lost cells and repairing neuronal circuitry, support cells are expected to aid in this process via secretion of diffusible factors (such as growth factors and cytokines) and contact-mediated cues. The ability of support cells to interact with stem cells, and secrete a wide range of molecules at physiologically relevant concentrations will result in a scaffold with greater degree of biomimcry. In fact, many studies have demonstrated the benefits of cocultures of glial cells (e.g., astrocytes) with neuronal cells in promoting overall cell survival and interaction with the scaffold $[9,115,116,129]$. Thus, incorporation of glia into scaffolds not only acts as a better physiological representation of the native cortical tissue, but it also imparts an added dimension of biochemical complexity that, thus far, cannot be 
replicated through control of the scaffold fabrication process alone. Furthermore, the inclusion of exogenous cells within scaffold microenvironments allows local sequestering of factors that are actively secreted by these cells.

\subsubsection{Scaffold Materials}

The success in any tissue engineering strategy requires the restoration of functional tissue, which usually depends on effective integration of an engineeredtissue construct with host tissue. The degree of tissue integration depends on both the interplay among various elements of the implanted scaffold with native functional tissue at the biomaterial interface, and matching of properties between implant and the host.

The design of a scaffold with suitable properties for tissue engineering can be considered as comprising of two main components - materials selection, and fabrication method. The fundamental role of scaffolds is to ensure cell survival, and to enable controlled proliferation and differentiation. In order to achieve this, the choice of material and fabrication method must take into account the primary requirements of a scaffold, which include the following:

- Biocompatibility

- The materials used must not be cytotoxic or immunogenic

- 3D architecture and pore structure

- High porosity will result in a large surface areato-volume ratio for cell attachment and interaction at the material interface

- Highly interconnected pores will enable cell infiltration and migration, as well as efficient mass transport and gas exchange of nutrients and metabolic waste

- Pore size will affect cell infiltration, migration, and orientation

- Appropriate structural morphology and topography will facilitate cell infiltration and help shape new tissue formation

- Controlled biodegradation

- Products of degradation should be noncytotoxic and bioresorbable

- Rate of degradation should match with the rate of new tissue formation
Given that success in BTE requires integration of regenerated cells with the existing functional neural circuit under in vivo conditions (i.e., following scaffold implantation), it is of primary importance that the foreign body response (FBR) is minimized. Any surgical implantation procedure in the brain will in itself elicit a multistaged inflammatory response that is mediated by microglia and astrocytes. The early phase of inflammation is considered a "destructive" response in which damaged or foreign tissue is removed by phagocytosis and cytotoxic molecules are secreted, which contribute to tissue necrosis. [2, 47, 138] Upon removal of all foreign material and damaged tissue, the inflammatory response transitions to a "cytotrophic" phase that aims to restore tissue integrity and cytoarchitecture through the secretion of anti-inflammatory cytokines, adhesive ECM molecules, and growth factors to facilitate neuronal regeneration [7, 132]. Disruptions to the events of inflammatory signaling between repairing cells can lead to chronic inflammation, where the initial cytotoxic phase is prolonged, leading to detrimental effects on the surrounding brain tissue. The continual presence of a foreign material, as in the case of an implanted scaffold, can upset this balance, leading to an extension of the FBR. In the context of brain repair, the ensuing encapsulation induced by the FBR is a detrimental process that will prevent integration of the implanted scaffold with the surrounding host tissue, impeding the re-integration of neuronal circuits.

It was originally proposed that the FBR was induced by biochemical reactions at the cell-scaffold interface because of nonspecific protein adsorption, acquired in vivo or in vitro, on the biomaterial surface [114]. This protein is detected by host immune cells and identified as foreign, which implies that the type of material and surface functionalization are critical factors determining the extent and severity of the FBR [88]. However, recent evidence suggests that pore size is a major contributing factor that promotes the healing of biomaterial implants by suppressing the effects of the FBR. Silicone elastomer and crosslinked poly(2-hydroxyethyl methacrylate) (PHEMA) were processed via sphere templating to create a scaffold with pores that were both highly uniform in size and highly interconnected. An optimal pore size of roughly $30 \mu \mathrm{m}$ was found to significantly reduce fibrosis and enhance vascularization compared to scaffolds of other pore size, when implanted in the heart muscle 
and percutaneously through the skin [113]. It is speculated that the attenuation of the inflammatory response is partly due to the ability of the pores to restrict macrophage migration, thus modulating their activity in the inflammatory response. In the delivery of a scaffold, the surgical implantation procedure will in itself elicit an inflammatory response. While inflammation is inevitable, it is actually an innate neuroprotective mechanism, aiding the healing process and providing a coordinated balance between damage control and tissue repair. Indiscriminate inhibition of cells mediating the inflammatory response (such as reactive astrocytes) can result in more damage by allowing widespread inflammation to run unabated in the initially unaffected neuronal tissue surrounding the injury site. [42, 94, 132] A key to successful tissue repair requires that such inflammatory response subsides gradually, without persisting as a chronic condition that will lead to a FBR. Recent studies within our group have investigated the inflammatory response associated with the implantation of poly-D-lysine (PDL)-modified xyloglucan hydrogels and electrospun poly( $\varepsilon$-caprolactone) (PCL) scaffolds, into the caudate putamen of rat brains [101]. These studies showed that the implants initially elicited an acute inflammatory response (peak response at 3 days post implantation), characterized by rapid migration of microglia and astrocytes to the implantation site. Staining for collagen III and IV (molecules secreted by reactive astrocytes that form part of the glial scar) showed no increase in the levels of these molecules at the implant-tissue interface. Furthermore, the presence and coexistence of astrocytes and neurites in the vicinity of the implant indicate the absence of scar tissue formation, and fibrous encapsulation (due to FBR), around the scaffold. In both cases, neurites from the surrounding host tissue were able to penetrate into the implanted scaffolds, the timing of which coincided with the attenuation of microglia cell numbers and a rise in astrocyte cell numbers. This signals the transition of the inflammatory response from a cytotoxic to cytotrophic phase, which may be essential in allowing the scaffold to present a permissive environment that encourages neurite infiltration and restoration of local cytoarchitecture (Fig. 22.2). Similar results have been observed in other types of scaffolds, such as hyaluronic acid (HA)-based [31, 59, 143] and poly[ $N$-(2-hydroxypropyl)-methacrylamide] (PHPMA) hydrogels [38, 39, 153], poly (glycolic acid) (PGA) fibrous scaffolds [107], and self-assembled nanofibrous scaffolds [40], following implantation into animal brains.

Controlled biodegradation of the scaffold during in vivo conditions is important because the long-term biocompatibility of any implanted material in a biological environment is questionable. Ideally, the scaffold only acts as a temporary substrate to support and guide tissue outgrowth. Gradual elimination of the scaffold will make space for new tissue formation; therefore, it is vital that the degradation rate matches with that of tissue formation. This is particularly important because scaffolds often present a highly permissive environment for cell ingrowth, but not necessarily cell outgrowth beyond the material to integrate with the host tissue. Often, additional cues may be required to direct neurite extension beyond the permissive scaffold environment, or alternatively, controlled scaffold degradation can force cells to gradually integrate and reform connections within the host brain. This is best depicted by the reciprocal interactions between NSCs preseeded in a micro-fibrous PGA scaffold and host tissue after implantation into a brain cavity caused by hypoxic ischemia [107]. Transplanted NSCs adhered and migrated through porous scaffolds and were able to differentiate into all three neural lineages (neurons, astrocytes, and oligodendrocytes) in vivo. There was also evidence that the implanted cells interacted with the network of neurons and oligodendrocytes that had infiltrated the scaffold from the host tissue. The gradual degradation of the PGA scaffold is believed to assist with the integration of the NSC-PGA complex with the host tissue, and the spontaneous cell ingrowth from the endogenous tissue, and cell outgrowth from within the transplant. In addition to providing a permissive environment, implantation of the NSC-PGA scaffold was associated with a reduction in the inflammatory reaction and astroglial scarring, both of which are adverse secondary processes caused by CNS injury that will otherwise impede neuronal regeneration.

The predominant biomaterials used in BTE are polymer-based because they have mechanical properties that are comparable to the native brain tissue, as well as flexibility in processing that allows for the fabrication of sophisticated structures and tailored properties (Table 22.1). A wide range of biomaterials, both naturally-derived and synthetic in origin, have been used under in vitro conditions to investigate the effectiveness of different strategies in guiding cell behavior. However, the choice of biomaterial becomes more 

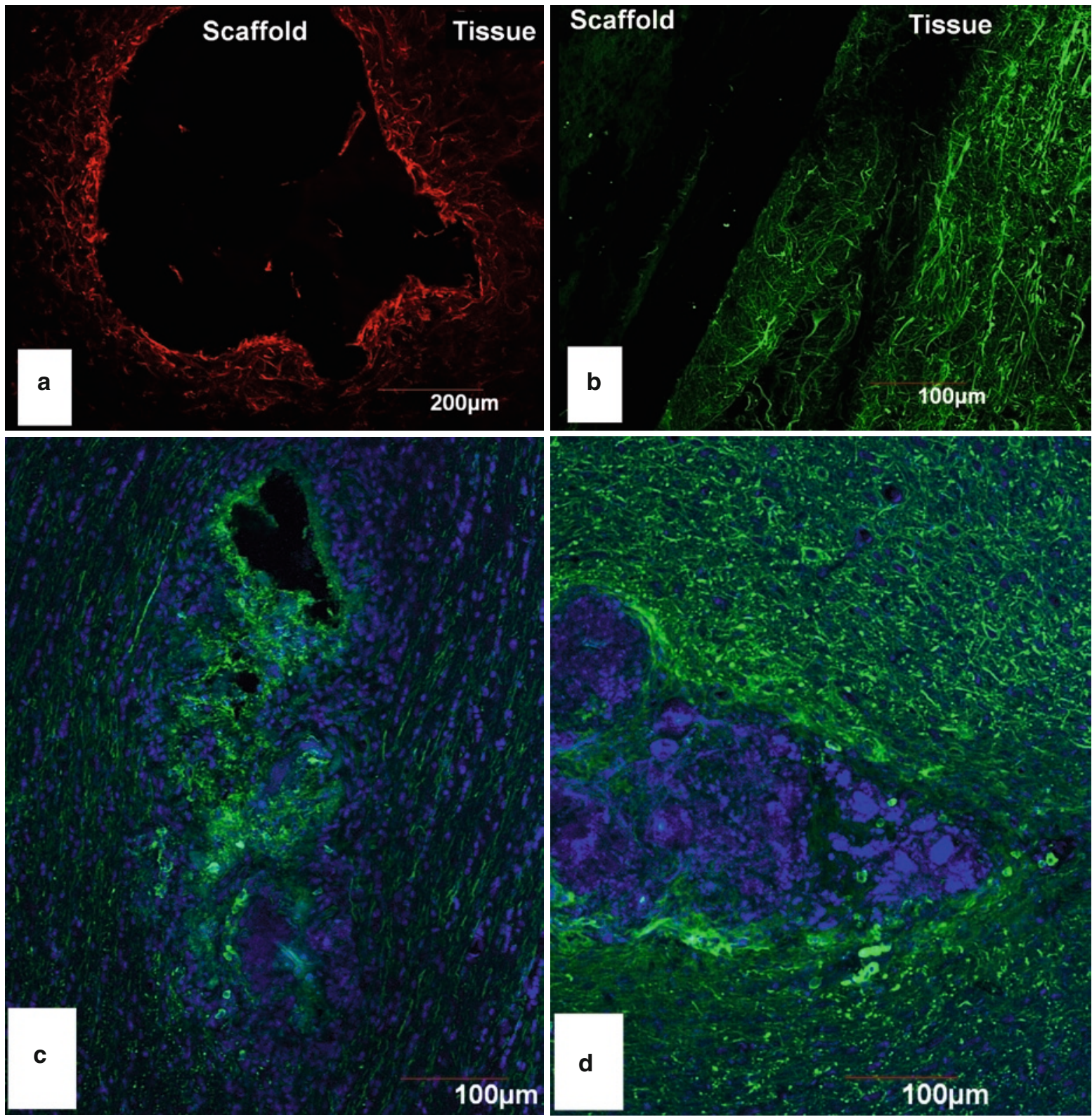

Fig. 22.2 Fluorescence images showing sections of electrospun PCL scaffolds (with randomly oriented nanofibers) (a, b) and poly-D-lysine (PDL)-modified xyloglucan hydrogels (c, d) 60 days after implantation into rat brains. The cross-section (a) and longitudinal section (b) of the implanted electrospun PCL scaffold (not immunostained) showing the coexistence of residual GFAP-positive astrocytes (red) and neurites (green) at the

restricted for in vivo applications because the material becomes exposed to a more complex environment where scaffold biocompatibility and biodegradability become more important. With the wide range of processing technologies available, the chosen biomaterial tissue-scaffold interface, indicating the absence of scar formation at the site of implantation. The longitudinal (c) and crosssection (d) of the implanted PDL-xyloglucan hydrogel, showing the infiltration of neurites (green) and other glia cells (DAPIstained; blue) into the scaffold. Cells infiltrating into the scaffold are disorganized in nature, which can be clearly distinguished from the highly organized endogenous tissue

can often be manipulated in an appropriate manner to yield a scaffold with the desired bulk mechanical and surface properties. The advantages associated with the use of naturally-derived polymers include the biological recognition that are sometimes intrinsically 
Table 22.1 List of scaffold materials that have been used for in vivo brain repair and their corresponding effectiveness to induce neural regeneration

\begin{tabular}{|c|c|c|c|c|}
\hline Material & $\begin{array}{l}\text { Scaffold structure and } \\
\text { properties }\end{array}$ & Implant site & In vivo response & References \\
\hline $\begin{array}{l}\text { Poly (glycolic } \\
\text { acid) (PGA) }\end{array}$ & $\begin{array}{l}\text { Woven array of PGA } \\
\text { microfibers (fiber } \\
\text { diameter of } 10-15 \mu \mathrm{m} \text { ) } \\
\text { Scaffolds were preseeded } \\
\text { with NSCs, which were } \\
\text { maintained for } 4 \text { days } \\
\text { prior to implantation }\end{array}$ & $\begin{array}{l}\text { Cerebral infarct in } \\
\text { mouse model of } \\
\text { hypoxic ischemia }(\mathrm{HI})\end{array}$ & $\begin{array}{l}\text { No glial scar formation at } \\
\text { scaffold-tissue interface } \\
\text { Neovascularization within } \\
\text { scaffold } \\
\text { Intricate reciprocal interactions } \\
\text { between implanted scaffold and } \\
\text { injured brain evident from the } \\
\text { extensive neurite ingrowth (from } \\
\text { host tissue) and outgrowth (from } \\
\text { seeded NSCs) }\end{array}$ & [107] \\
\hline $\begin{array}{l}\text { Poly }[N-(2- \\
\text { hydroxypropyl)- } \\
\text { methacrylamide }] \\
\text { (PHPMA) }\end{array}$ & $\begin{array}{l}\text { 3D hydrogel structure- } \\
\text { Modified with } \\
N \text {-acetylglucosamine } \\
\text { (NacGlc) groups to } \\
\text { improve interaction with } \\
\text { cells }\end{array}$ & $\begin{array}{l}\text { Frontal cortex of adult } \\
\text { rats }\end{array}$ & $\begin{array}{l}\text { No discernable macroscopic } \\
\text { inflammationGood integration of } \\
\text { scaffold with host brain tissue } \\
\text { (esp. in NacGlc-PHPMA) } \\
\text { Scaffold provided a permissive } \\
\text { environment for cell infiltration } \\
\text { and axon ingrowth } \\
\text { When preseeded with fetal } \\
\text { neurons, target reinnervation was } \\
\text { partially achieved, but did not } \\
\text { lead to functional recovery in } \\
\text { corresponding cognitive functions }\end{array}$ & {$[38,39,153]$} \\
\hline $\begin{array}{l}\text { Hyaluronic acid } \\
\text { (HA) }\end{array}$ & $\begin{array}{l}\text { 3D hydrogel structure- } \\
\text { Modified with poly-D- } \\
\text { lysine (PDL), laminin, } \\
\text { and RGD to increase cell } \\
\text { infiltration }\end{array}$ & $\begin{array}{l}\text { Frontal cortex of adult } \\
\text { rats }\end{array}$ & $\begin{array}{l}\text { In all unmodified and modified } \\
\text { HA scaffolds } \\
\text { Transient localized inflamma- } \\
\text { tion only at lesion site } \\
\text { No glial scar formation at } \\
\text { scaffold-tissue interface } \\
\text { Integration with host tissue } \\
\text { Collagen deposition associated } \\
\text { with cell infiltration into scaffold } \\
\text { Angiogenesis around and within } \\
\text { implant } \\
\text { Biodegradable - complete } \\
\text { resorption within } 12 \text { weeks post } \\
\text { implantation } \\
\text { Modification with PDL, laminin, } \\
\text { or RGD led to greater amount of } \\
\text { glial cell infiltration, compared to } \\
\text { unmodified HA hydrogels } \\
\text { Neurite regrowth observed only } \\
\text { within HA hydrogels modified } \\
\text { with laminin or RGD }\end{array}$ & {$[31,59,143]$} \\
\hline Chitosan & $\begin{array}{l}\text { Thermosensitive hydrogel } \\
\text { formed in situ Modified } \\
\text { with poly-D-lysine (PDL) } \\
\text { to improve interaction } \\
\text { with neuronal cells and } \\
\text { promote neurite } \\
\text { outgrowth }\end{array}$ & Striatum of adult rats & $\begin{array}{l}\text { Completely engulfed by } \\
\text { macrophages within } 3 \text { days post } \\
\text { implantationPDL-modification } \\
\text { had no effect on inflammatory } \\
\text { response }\end{array}$ & [29] \\
\hline
\end{tabular}


Table 22.1 (continued)

\begin{tabular}{|c|c|c|c|c|}
\hline Material & $\begin{array}{l}\text { Scaffold structure and } \\
\text { properties }\end{array}$ & Implant site & In vivo response & References \\
\hline Xyloglucan & $\begin{array}{l}\text { Thermosensitive hydrogel } \\
\text { formed in situ Modified } \\
\text { with PDL to improve } \\
\text { interaction with neuronal } \\
\text { cells and promote neurite } \\
\text { outgrowth }\end{array}$ & $\begin{array}{l}\text { Caudate putamen of } \\
\text { adult rats }\end{array}$ & $\begin{array}{l}\text { Transient localized inflammatory } \\
\text { response, but no glial scar } \\
\text { formation around implant } \\
\text { Presence of immobilized PDL } \\
\text { had no significant influence on } \\
\text { microglial response, where } \\
\text { microglial cell numbers peaked } 3 \\
\text { days post implantation, and } \\
\text { subsided to normal physiological } \\
\text { levels by } 21 \text { days } \\
\text { Higher PDL content enabled } \\
\text { astrocytes to infiltrate scaffold } \\
\text { Neurites infiltrated PDL-modified } \\
\text { xyloglucan scaffolds only, an } \\
\text { increase in PDL content led to } \\
\text { increased neurite density within } \\
\text { the scaffold }\end{array}$ & [101] \\
\hline $\begin{array}{l}\text { Poly } \\
\text { ( } \varepsilon \text {-caprolactone) } \\
\text { (PCL) }\end{array}$ & $\begin{array}{l}\text { 3D array of nonwoven } \\
\text { electrospun nanofibers } \\
\text { that are either aligned or } \\
\text { randomly oriented }\end{array}$ & $\begin{array}{l}\text { Caudate putamen of } \\
\text { adult rats }\end{array}$ & $\begin{array}{l}\text { Transient localized inflammatory } \\
\text { response, but no glial scar } \\
\text { formation around implants } \\
\text { Neurites only infiltrated scaffold } \\
\text { with randomly oriented PCL } \\
\text { nanofibers, and coincided with } \\
\text { the decline in activated microglial } \\
\text { cells and maximum number of } \\
\text { activated astrocytes } \\
\text { Neurites crossed perpendicular to } \\
\text { the direction of fiber alignment } \\
\text { (i.e., perpendicular contact } \\
\text { guidance) }\end{array}$ & [102] \\
\hline $\begin{array}{l}\text { RADA 16-I } \\
\text { Self-assembling } \\
\text { peptide nanofiber } \\
\text { scaffold (SAPNS) }\end{array}$ & $\begin{array}{l}\text { 3D hydrogel-like scaffold } \\
\text { consisting of a network of } \\
\text { interwoven nanofibers } \\
(\sim 10 \mathrm{~nm}) \text { formed in situ }\end{array}$ & $\begin{array}{l}\text { Superior colliculus (SC) } \\
\text { (midbrain) of postnatal } \\
\text { (P2) and adult hamsters }\end{array}$ & $\begin{array}{l}\text { No scar tissue formation around } \\
\text { implanted scaffold Seamless } \\
\text { integration between scaffold and } \\
\text { host brain tissue } \\
\text { Axonal regrowth across the } \\
\text { scaffold resulted in reinnervation } \\
\text { of the SC, and return of } \\
\text { functional vision within } 6 \text { weeks } \\
\text { post implantation }\end{array}$ & [40] \\
\hline
\end{tabular}

present, as well as promoting certain cellular functions; such materials can potentially be enzymatically degraded in vivo giving noncytotoxic and resorbable degradation products. However, the use of naturally derived materials is often limited by their immunogenicity, poor mechanical properties, and batch-to-batch variations. In contrast, synthetic biomaterials can be processed in a more reliable manner, with a wide range of mechanical properties possible; however, such materials often require surface biofunctionalization to support various cellular functions. It is becoming increasingly common to find a middle ground between the extremes of biologically derived and synthetic polymers such as bioconjugates or blends. The materials selection process will also partially dictate the fabrication technique that can be used, and the subsequent types of morphologies that can be achieved. The scaffold morphologies commonly used in BTE can be broadly divided into two categories - hydrogel and fibrous structures. 


\subsubsection{Hydrogels}

Hydrogels are 3D polymer networks that are chemically and/or physically crosslinked, forming an insoluble network of polymer chains that swell under aqueous conditions. Thus, hydrogels can be used as a synthetic analog of the hydrated network of insoluble macromolecules that naturally exist in the extracellular environment. Owing to the highly hydrophilic nature of the polymer chains, hydrogels have very high water content, as well as high permeability to oxygen and nutrients [98]. In addition, their crosslinked molecular architecture results in materials with mechanical properties similar to brain tissue. Hydrogels also have a very low interfacial tension, which aids in tissue integration by minimizing the barrier for cells to cross the scaffold-tissue boundary [98]. All these features make hydrogels an ideal choice of material to support brain tissue growth and survival both in vitro and in vivo.

Hydrogels can be formed via the addition of chemical crosslinkers that form a covalent network of polymer chains, or via the formation of physical junctions through secondary interactions, crystallite formation, or chain entanglements. The gelation behavior of many physically crosslinked hydrogels can be reversed in response to externally-applied stimuli such as temperature, $\mathrm{pH}$, and ionic strength of the surrounding solution. This property is due to changes in the enthalpy and entropy associated with various interactions within a polymer solution (i.e., polymer-polymer, polymer-water, and water-water interactions). Many hydrogel materials can be modified in terms of monomer composition to allow gelation to occur during transition from ambient to physiological conditions. This is highly advantageous because such thermally sensitive hydrogels are injectable, resulting in a scaffold that can conform to the shape of any lesion, and can be implanted in a minimally invasive manner, even within deep brain structures.

Hydrogels present a unique microstructure to cells, which is characterized by its highly interconnected porous structure and high surface area. The precise microstructure depends on the conditions of gel preparation, including polymer concentration and speed of gelation. The most commonly observed macroporous hydrogel microstructures consist of an interconnected fiber-like morphology, laths or sheets that are interconnected by thin struts, and heterogeneous microstructures (Fig. 22.3), all of which can impart different mechanical properties to the material.
Hydrogels are often used as vehicles for encapsulation and subsequent delivery of therapeutic drugs, growth factors, and cells to sites of injury to promote regeneration. In cases where large volumes of neuronal tissue are lost, cells can be encapsulated into the polymer solution prior to implantation into the brain, thus acting as an exogenous source of cells. In addition, the hydrogel can be modified with specific biochemical properties and structural morphology to enable in vitro expansion of NPCs, followed by the direct implantation of the cell-encapsulated hydrogel, eliminating the need to remove cells from a substrate prior to implantation. The highly-hydrated nature, porous structure, and 3D micro-architecture of some hydrogels often present a permissive environment for cell growth when implanted in vivo, which is characterized by exuberant neurite ingrowth and glial cell invasion [38, 39, 153]. This extensive interaction between host cells and the hydrogel scaffold can be further promoted by adsorption of host-secreted adhesive ECM proteins such as fibronectin [39]. Despite this permissive environment, neurite outgrowth and subsequent target reinnervation are rarely observed [39], strongly suggesting that additional attractive cues are required to direct neurites beyond the hydrogel to reform appropriate connections. When hydrogel implants are used in combination with cell grafts to treat lesions within the septo-hippocampal pathway in the rat brain, partial reinnervation of the hippocampus has been observed at the tissue-scaffold interface [38]. This partial reinnervation was able to attenuate lesion-induced hyperactivity in the hippocampus, but was ineffective in reversing damages inflicted on behavioral and cognitive functions, which may be a reflection of the inadequacy in quantity and/or specificity of the new neuronal connections. Controlled degradation of hydrogel scaffolds is one approach to potentially improve reinnervation efficiency within a hydrogel by gradually exposing implanted cells to the host tissue.

Biodegradability and the rate of degradation can often be manipulated by incorporation of degradable units or crosslinkers into the synthetic hydrogel. Control over the degradation rate allows intimate control over the temporal evolution of the hydrogel's morphology in terms of its mesh size, which can in turn affect the proliferation of encapsulated precursor cells. Gradual degradation of a hydrogel material is important for tissue engineering applications because it will create free space for cells to proliferate, migrate, 

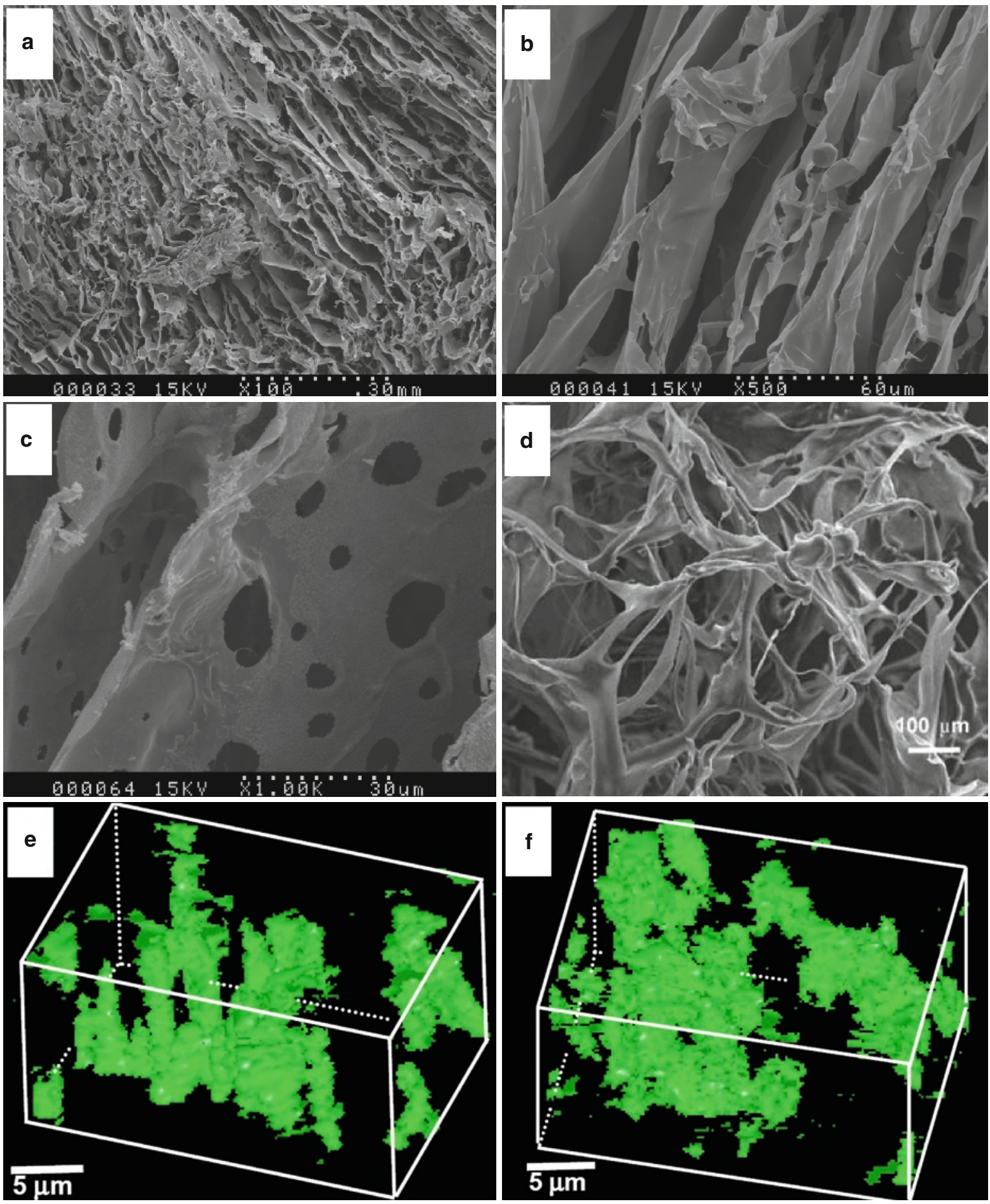

Fig. 22.3 SEM and LCSM images of different hydrogel materials, illustrating the different types of morphology that can be obtained, as well as the highly interconnected porous structure. (a-c) SEM images of xyloglucan hydrogels at various magnifications, showing sheet-like lamellar structures, and pores within individual sheets (c). (d) SEM image of hyaluronic acid (HA) hydrogels displaying flake-like morphology that are interconnected by fibrous structures; scale bar $=100 \mu \mathrm{m}$. (e, f) 3D visu-

alizations of chitosan/GP hydrogels obtained using stacked LSCM images, where chitosan agglomerates to form either chain-like structures $(0.25 \% \mathrm{w} / \mathrm{v}$ chitosan) (e) or polymeric aggregates $(1.0 \% \mathrm{w} / \mathrm{v}$ chitosan) (f). (d) Reproduced with permission from Springer Science+Business Media Cui et al.[32], (e, f) Reprinted from Biophysical Chemistry [28], Copyright (2005), with permission from Elsevier 
as well as an opportunity for cells to remodel and define their local microenvironment by depositing their own ECM molecules. Degradable hydrogels of poly(ethylene glycol) (PEG) were synthesized via the addition of methacrylate groups as crosslinking agents, and degradable functionalities were incorporated into the polymer in the form of PGA and poly(lactic acid) (PLA). NPCs encapsulated within the degradable PEG hydrogel survived the photo-polymerization process, and remained viable and proliferative after 16 days of culture. The time scale over which cell proliferation and spatial patterning of neuronal tissue formation occurred was controlled by the rate of degradation, which in turn was tailored by altering the relative composition of the degradable macromers [86]. Proteolytic susceptibility can also be engineered into hydrogel scaffolds such that degradation is dependent on the secretion of specific enzymes from cells $[85,111,127,150]$. Proteolytic degradation is often localized to pericellular components of the ECM because of the involvement of membrane-bound proteases, which enables the structural stability of the bulk of the scaffold to be maintained for longer periods of time. Furthermore, such cell-mediated degradations allow scaffolds to behave in a dynamic and biologically responsive way, making them more biomimetic, and offering cells greater control over the remodeling process of their microenvironment.

Mechanical properties of the hydrogel such as elasticity are also tuneable by controlling crosslink density, which has been shown to be effective in controlling the rate of neurite outgrowth on different hydrogel materials including agarose [6], collagen [151], and DNA-crosslinked gels based on polyacrylamide [67]. There is strong evidence that cells can sense substrate stiffness via integrin-based adhesions with the substrate. Cellular mechano-transduction leads to rearrangement of the cytoskeleton, which may ultimately affect neurite outgrowth morphology. Substrate stiffness is a regulator of neurite branching and axonal regeneration, and can control neuronal and astroglial populations because of differing degrees of attachment as a consequence of substrate stiffness [68]. However, the effect of substrate stiffness on neurite extension is still under debate. Confounding factors in this regard may reflect the method in which substrate stiffness is manipulated; agarose and collagen gels of different stiffness were obtained by altering gel concentration. As both these materials are known to possess adhesive domains that can interact with cells, it is possible that neurite outgrowth was affected not only by gel stiffness, but also by the concomitant changes in ligand density associated with changes in gel concentration. Therefore, excessive adhesive interactions between cells and substrates could have slowed the rate of neurite extension. Recently, a novel method of designing gels of different stiffness without changing the surface ligand density was developed by using DNA as a crosslinker [67]. Increasing the gel stiffness up to $17.1 \mathrm{kPa}$ decreased neurite extension and increased the number of primary dendrites, suggesting that distinct sensitivity and a threshold exists for dendrite and axonal extension [67]. It is also likely that the optimum substrate stiffness for neurite outgrowth will vary for different neuronal phenotypes.

HA hydrogels is one of a few materials that have been shown to minimize the FBR, which is the major reason behind their ability to integrate with the host tissue after implantation $[31,59,143]$. HA is an important natural component of the ECM in the brain as well as an important coregulator of human ESCs in vitro and in vivo [49]. While 3D hydrogels of HA are ineffective in promoting neurite outgrowth due to a lack of cell adhesion on the substrate, hydrogels consisting of copolymers of HA and PLL are effective in promoting neuronal repair by minimizing scar formation at the scaffold-tissue interface. When implanted into the rat brain, these materials only evoked a transient and localized inflammatory reaction, which began to subside after 3 weeks [143]. Chitosan hydrogels have also been shown to be a promising material for BTE applications, where properties such as degradation behavior can depend on the degree of deacetylation (DD). Chitosan has been considered a potential scaffold material for long-term implantation because of its biocompatibility with neurons [21, 52, 64-66], and at high DD they induce minimal inflammation with relatively slow degradation rates [144]. However, upon injection of an in situ forming tract of thermoresponsive chitosan into rat brains, it was found that the material was promptly engulfed by macrophages as part of the FBR [29]. Therefore, while scaffolds can be optimized with various physical and chemical properties to control cell behavior, it is equally important to determine the body's response to the implanted materials under relevant conditions to ensure that cellular responses achieved in vitro can be replicated in vivo. 
Despite the flexibility in processing of hydrogels to generate tailored features, it is difficult to control the direction of neurite outgrowth, which is one of the most important requirements in neuronal regeneration. Advances in fabrication technologies have enabled the use of scaffolds with tailored micro- and nano-scaled features, emulating the intricate fibrillar architecture of natural ECM components, as a tool for directing neurite outgrowth.

\subsubsection{Fibrous Structures}

The ability of fibrous scaffolds to support cell survival may be at least partially due to the high surface areato-volume ratio for optimal cell attachment and interaction with the material. However, there is strong evidence that the fibrous architecture itself is an important feature in supporting cell viability, and influencing subsequent cell morphology. The three main techniques used to fabricate 3D fibrous structures for BTE include thermally-induced phase separation (TIPS), electrospinning, and self-assembly.

In TIPS, a homogeneous polymer solution is cooled in order to induce phase separation via spinodal decomposition, where the resultant morphology consists of fibrous structures, with high porosity and interconnected pores. The thermodynamic equilibrium phase of a polymer solution can be determined from a phase diagram. For a typical polymer/solvent binary system, a binodal curve exists, above which the equilibrium phase is a homogeneous solution, and below which it is a mixture of solvent-rich and polymer-rich phases. When a polymer solution is cooled to within metastable regions below the binodal curve, phase separation will occur via nucleation and growth mechanisms, leading to a microstructure where component phases are present as discontinuous structures. In contrast, when a polymer solution is cooled to within an unstable region below the binodal curve, phase separation occurs via spontaneous demixing (spinodal decomposition), resulting in a microstructure where polymer and pores are cocontinuous in nature, leading to pore interconnection. Using such a method, nanofibrous PLLA structures have been fabricated, with fiber diameters in the range of 50-350 nm, and porosity of approximately 85\% [157] (Fig. 22.4). Feature dimensions were manipulated by systematic variations of polymer concentration (in the range of $2-9 \% \mathrm{w} / \mathrm{v})$. Such scaffolds were able to support the attachment of neonatal mouse NSCs, and their subsequent differentiation into neurons, which migrated into the porous scaffold [157]. Despite the simplicity and versatility of this technique, aligned features are not easily incorporated.

Electrospinning is another simple and inexpensive method for producing polymeric scaffolds with highly interconnected porosity and fibrous structures with fiber diameters in the range of nano- to micro-meters (Fig. 22.5). Fiber orientation can be developed by using different collection methods [140]. Aligned fibers have been obtained by collecting electrospun fibers on a rotating mandrel [158], dual rings [32], or across an insulative gap between two conductive strips [79]. Fibers form a parallel array across an insulative gap because of the electric field associated with such a configuration, and electrostatic interactions between depositing fibers.

Electrospun polymeric materials are capable of supporting the attachment, growth, and proliferation of various neuronal stem and progenitor cells in vitro [23-26, 50, 99, 129, 154, 158]. It has been shown that fiber diameter alone is capable of influencing cell behavior. Rat NSCs cultured on electrospun polyethersulfone (PES) scaffolds with increasing fiber diameters (in the range $280-1,450 \mathrm{~nm}$ ), showed an associated decrease in cell proliferation [26]. Cells on $283 \mathrm{~nm}$ fibers displayed a more rounded morphology compared to larger diameter fibers, as well as moderate spreading. In contrast, cells cultured on larger diameter fibers exhibited lower migratory activity and tended to form large cellular aggregates. The lower cell viability on larger diameter fibers is a result of poorer cell attachment and limited migratory ability, which may be mediated by poor cell spreading on the substrate, and the subsequent cytoskeletal arrangement due to lack of actin fiber formation.

Cell-scaffold interactions can be further enhanced by optimizing surface properties of the electrospun fibers. Cell attachment and subsequent proliferation can be increased by presenting amine moieties on the surface of electrospun PCL scaffolds [101]. The incorporation of bioactive ECM and ECM-like components, including laminin, collagen, and gelatin, as a blend in the electrospinning polymer solution, is an effective method of improving attachment and subsequent proliferation and survival of various cell types, including NSCs, DRG explants and PC12 cells, in vitro [50, 74, 129]. As laminin and collagen are major components 

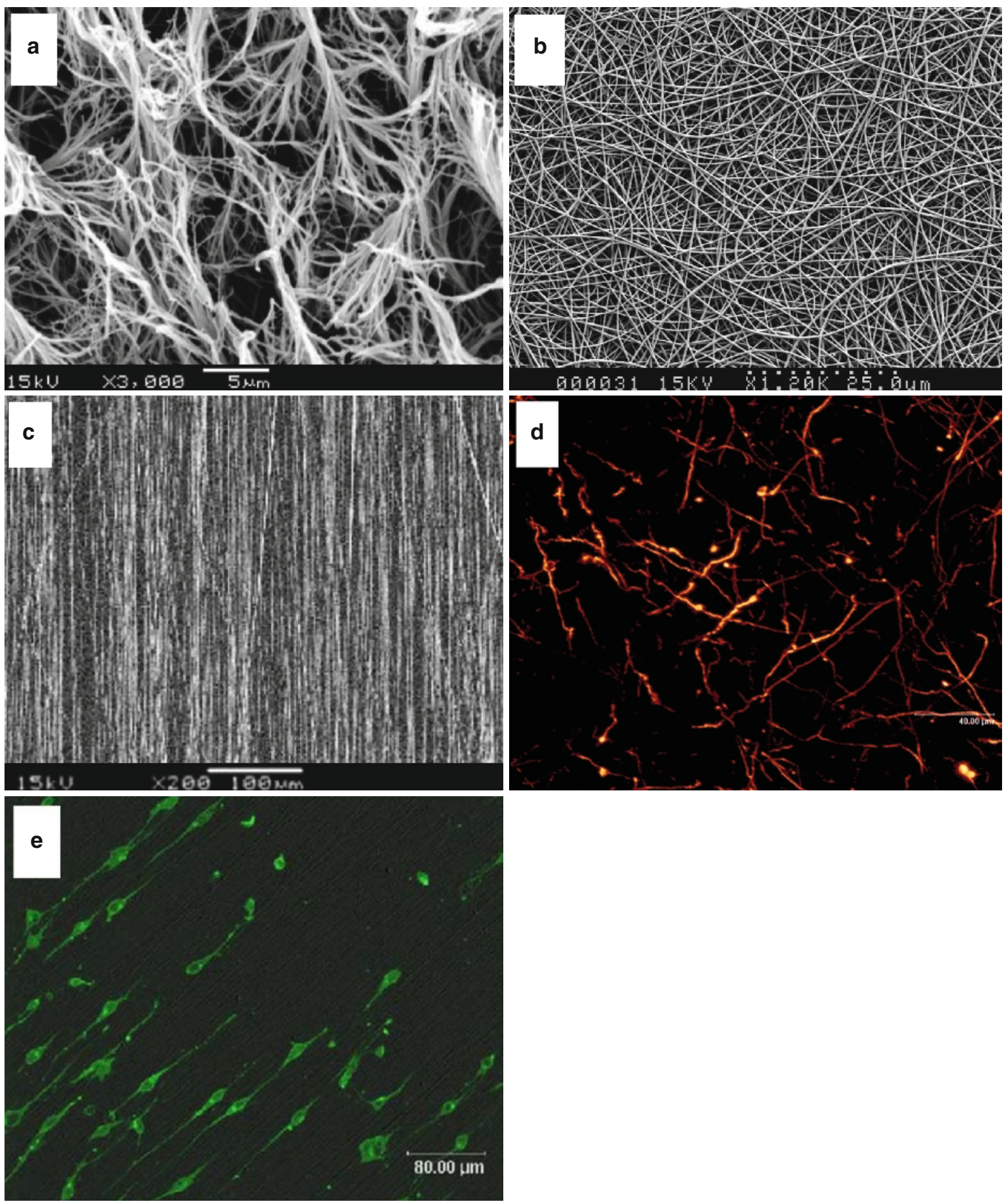

Fig. 22.4 SEM images of nanofiber morphology obtained via thermally-induced phase separation (TPS) (a) and electrospinning $(\mathbf{b}, \mathbf{c})$. Electrospun nanofibers can be collected as a nonwoven array of randomly oriented (b) or aligned (c) polymer fibers. Fluorescent images of (d) primary cortical neurons cultured on randomly oriented electrospun PCL nanofibers, and (e) neonatal mouse C17.2 neural stem cells (NSCs) cultured on aligned elec- trospun PLLA nanofibers, showing the ability of fiber alignment to provide contact guidance cues to guide neurite outgrowth in the direction of fiber alignment. (a) Reprinted from Biomaterials, Yang et al. [157], Copyright (2004), with permission from Elsevier. Fig (c, e) Reprinted from Biomaterials, Yang et al. [158], Copyright (2005), with permission from Elsevier 
a
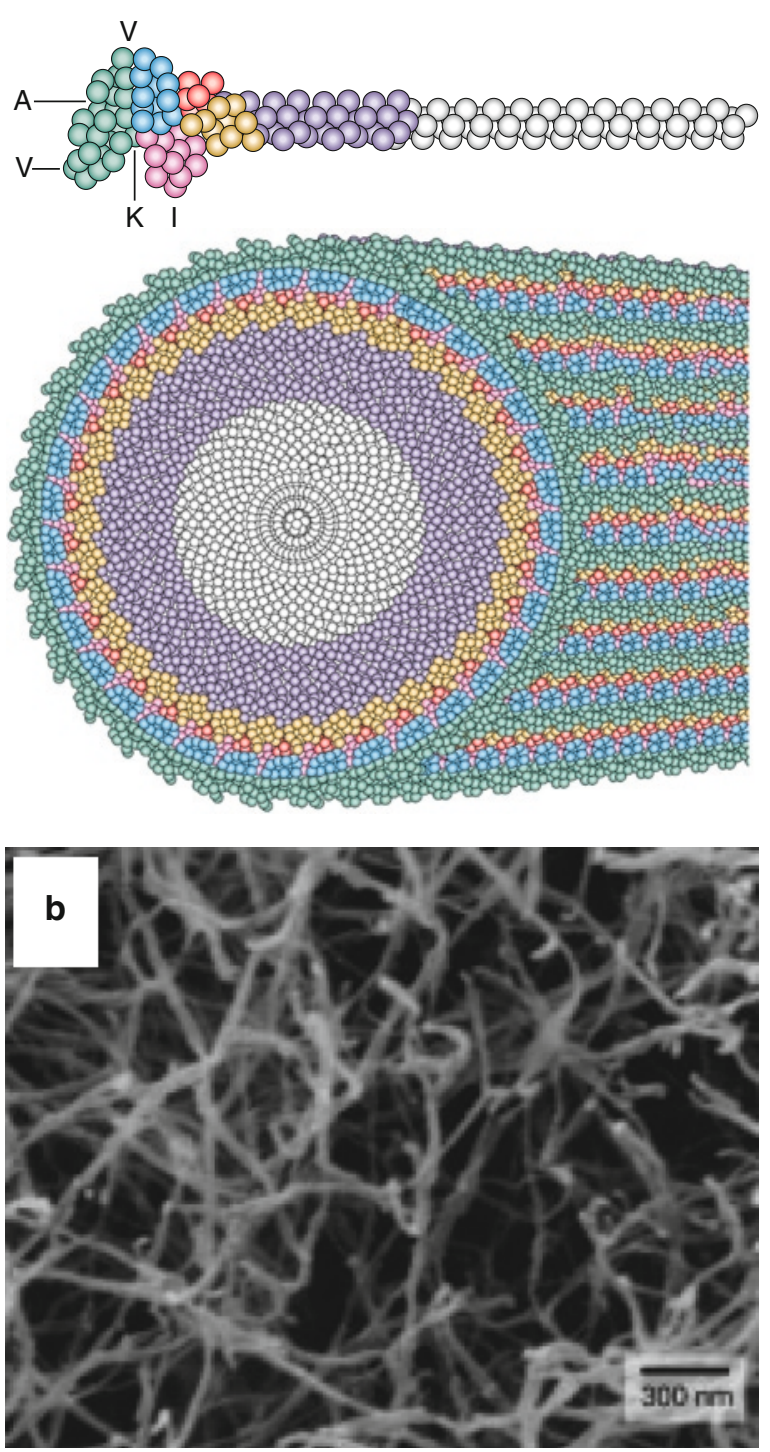

Fig. 22.5 Schematic molecular structure of self-assembled nanofibers from peptide amphiphilic molecules (a), and the corresponding structural morphology of the self-assembled nanofibers as depicted from SEM imaging (b). Reprinted from [130] with permission from AAAS

of the brain ECM, both are readily recognized by neuronal cell receptors for attachment; hence, improved cell viability is likely to be related to the ability of cells to interact via such cell adhesion molecules on the fiber surface.

The diameters of electrospun fibers can have potent effects on the differentiation of cultured NSCs. The differentiation specification of rat NSCs varies depending on the average diameter of electrospun fibers [26]. Compared to cells on control tissue-culture plastic surfaces (TCPS), there was a three-fold increase in oligodendrocyte differentiation on $273 \mathrm{~nm}$-fibers, and the highest fraction of neuronal differentiation was observed on $749 \mathrm{~nm}$-fibers. The migratory ability of differentiating cells enabled the electrospun fibers to guide the extension of cell processes, determining cell morphology and possibly supporting differentiation into different cell types. Electrospun PLLA nanofibers with average fiber diameters in the range of 250 and $300 \mathrm{~nm}$ strongly supported the differentiation of mouse NSCs into neurons compared to micron-sized fibers [158]. However, only markers for NSC differentiation toward neurons were used; hence, it is possible that cells had a similar differentiation profile.

Fiber alignment also influences the differentiation of cultured NSCs. The differentiation profile of murine ESCs cultured on electrospun PCL nanofibers (average fiber diameter approximately $250 \mathrm{~nm}$ ) varied depending on whether fibers were aligned or randomly orientated [154]. While it was shown that culturing ESCs on nanofibrous PCL scaffolds induced differentiation into various neural lineages (including neural precursors, neurons, oligodendrocytes, and astrocytes), a significantly greater proportion of ESCs differentiated into astrocytes on randomly oriented PCL nanofibers compared to aligned PCL. Interestingly, Yang et al. reported that the rate of neuronal differentiation appeared to be independent of fiber alignment on both electrospun PLLA nano- and micro-fibers [158].

Collectively, the results of recent studies indicate that fiber diameter and alignment of electrospun fibers can influence the differentiation characteristics of NSCs. For instance, Nisbet [101] reported the preferential differentiation of rat brain-derived NSCs into oligodendrocytes, with no neuronal differentiation on electrospun PCL fibers with average diameters of $750 \pm 100 \mathrm{~nm}$; the differentiation profile was not affected by surface aminolyzation [101]. These ambivalent results may be a reflection of differences in materials and/or cell types used in the separate studies. For instance, each scaffold may display different surface chemistry and substrate stiffness, all of which can have varying effects on cellmaterial interactions and subsequent differentiation. Also, variability in fiber diameters within electrospun scaffolds may mask the true effect of fiber diameters on 
cell behavior. Such preliminary studies provide evidence that differentiation specification may be mediated by variable cell adhesion onto fibrous surfaces, which can affect cell morphology, cytoskeletal arrangement, and the subsequent cell signaling that ultimately affects cell fate. While the exact mechanism by which fiber diameter and alignment can affect differentiation remains to be determined, it is clear that these are only two of the many cues that can be used to modulate cell behavior.

One of the main advantages of using nanofibrous scaffolds in BTE is their potential to guide neurites toward target locations utilizing aligned fiber morphologies. Many studies have shown the effectiveness of aligned electrospun nanofibers in not only guiding process outgrowth, but also supporting and enhancing the rate of process elongation $[23,24,50,73,101$, $129,154,158]$. In general, cells cultured on aligned nano/ micro-fibrous substrates display a bipolar morphology, with cell body elongation occurring in the direction of fiber alignment. This suggests that aligned nanofibers can act as a positive guidance cue for directed neurite outgrowth. This process is more broadly known as "contact guidance," where direct contact-mediated interactions between the advancing growth cone and aligned fiber surfaces can direct neurite outgrowth. Experimental results have shown that neurites initially protruding from the neuronal cell body do not necessarily follow the direction of immediately adjacent fibers (or any other aligned topographical features) [87, 116, 129]. However, when the growing neurite comes into contact with a nanofiber that is part of an oriented assembly, it is capable of making sharp turns in order to continue following the underlying fiber. It is interesting to note that guidance of process outgrowth by aligned fibers is not restricted to neuronal cell types, but also applies to glial cells such as Schwann cells and astrocytes. In fact, in cell cultures containing both glia and neuronal cell types, glia cells are often in direct contact with the underlying fiber substrate, with neurons growing on top of the glia cells, such that any physical orienting effects from the substrate is mediated through contact between neuronal and glia cells $[9,116,129]$. There is also evidence that the guidance provided by aligned electrospun nanofibers is related to other factors such as fiber diameter and interfiber distance. Observations of the interactions between growing cortical neurons and randomly oriented nanofibers revealed that neurite outgrowth does not necessarily follow the underlying fibers. The direction of neurite outgrowth relative to the nanofibers was dependent on the interfiber distance; neurites were more inclined to follow a fiber if interfiber distances were relatively large $(>15 \mu \mathrm{m})$, traverse perpendicular to the polymer nanofibers if interfiber distances were relatively small (2-15 $\mu \mathrm{m})$, and completely avoided regions of high fiber density (interfiber distance less than $1 \mu \mathrm{m}$ ) [100].

The precise mechanism via which fiber diameter, alignment and spacing affect various aspects of cell behavior is yet to be elucidated. Difficulties in fabricating electrospun scaffolds with highly defined fiber diameters and interfiber distances mean that any observed changes in cell behavior cannot be solely attributed to one scaffold parameter alone. In particular, variations in fiber diameters or alignment also lead to concomitant changes in the pore structure of the scaffold in terms of interfiber distance and pore shape. However, recently, ice crystals were used as a removable void template for electrospinning nanofibrous scaffolds with variable interfiber distance, which can potentially enable the effects of fiber diameter and interfiber distance to be decoupled [131]. Furthermore, the use of different materials in different studies makes direct comparison of cell behavior difficult. Nevertheless, current experimental evidence suggests that the morphology of electrospun scaffolds can have beneficial effects on the manipulation of various progenitor cells for BTE. Moreover, it appears that scaffold structure can influence cell adhesion, and subsequent development of cell morphology and cytoskeletal arrangement, which may in turn affect the cells migratory ability, differentiation specification, process outgrowth, and maintenance of viability.

Self-assembly is a bottom-up nanofabrication approach that can be used to generate 3D fibrous structures with fiber diameters in the order of $10^{\circ}-10^{1} \mathrm{~nm}$. This method exploits the spontaneous association of certain molecules, under thermodynamic equilibrium conditions, to form ordered structures via noncovalent bonds. The building blocks of self-assembled nanofibers are often synthetically designed amphiphilic oligopeptides, consisting of specific sequences of amino acids [161]. Therefore, self-assembled nanofibers are often biodegradable, with noncytotoxic by-products. Self-assembled nanostructures are often designed to form under physiological conditions, enabling injection 
into the brain as a solution to form a hydrogel-like material in situ. Self-assembled nanofibrous scaffolds typically consist of interwoven nanofibers with diameters in the order of $10 \mathrm{~nm}$ and pore sizes of 5-200 nm, and exist in a highly-hydrated state (water content up to $99.5 \% \mathrm{w} / \mathrm{v}$ ) [161]. In addition to supporting neuronal differentiation and neurite outgrowth in vitro [58], self-assembled nanofibers are also capable of encouraging neuronal regeneration such as across transected optic nerve fibers in the superior colliculus, enabling restoration of functional vision in rodent models [40]. Integration of the self-assembling peptide nanofiber scaffold (SAPNS) at the sites of inducedlesions was also correlated to the degree of reinnervation in the superior colliculus, suggesting sufficient reinstatement of neuronal connectivity. Maintenance of a well-organized tissue structure at the injury site may have suppressed inflammation by controlling the infiltration of inflammatory cells to the scaffold-tissue interface. The presence of high levels of the RAD sequence (similar to the RGD motif found in adhesive ECM proteins) in the scaffold suggests that neuronal cell attachment, neurite outgrowth, and tissue remodeling are highly regulated by defined cell-substrate adhesion mechanisms.

Despite the ability of self-assembled nanofibers to support neuronal differentiation and neurite outgrowth both in vitro $[58,130]$ and in vivo [40, 147], the lack of alignment within the fabricated structure means that, by itself, it may not provide sufficient physical cues to direct neurite outgrowth. However, one of the major advantages of this fabrication method lies in its ability to efficiently present high densities of biologicallyactive ligands on the surface for cell recognition, which will be discussed below.

\subsubsection{Biofunctionalization}

The ability of biomaterials to influence cell behavior is initiated by interactions occurring at the cell-scaffol interface, and hence the importance of surface biofunctionalization. The motivation for biofunctionalization is to design biomimetic surfaces that encourage tissue integration with the scaffold, and to regulate cellular behavior. This often involves the immobilization of cell-signaling molecules onto the surface to better control cell behavior by targeting receptor-mediated cellular mechanisms. Table 22.2 presents a list of different bioactive molecules that have been used to biofunctionalize scaffolds for BTE applications. Surface biofunctionalization seeks to control the presentation of proteins to cells in such a way to enhance selective aspects of cell behavior and in some instances, limit nonspecific protein adsorption. Due to synergistic substrate and growth-factor effects, two goals of biofunctionalization are:

- Promote and maintain cell survival and proliferation via ligand signaling

- Enable cells to physically interact with the substrate such that subsequent cell growth and migration can be guided by the underlying structural/physical features

It is often desirable to present bioactive molecules on a scaffold in an immobilized form, as opposed to soluble form, because it will not be internalized by cells or dissipated because of diffusion. Therefore, immobilized biomolecules are capable of having a sustained and localized effect on cells. They influence cell behavior via activation of signaling pathways through specific ligand-receptor binding; whereas soluble factors can also potentially influence other cell functions including gene expression and apoptosis after they have been internalized and delivered toward the soma via retrograde transport [71]. Regardless of the optimal delivery method, functionalization of scaffold surfaces with biomolecules provides a flexible means of ligand presentation directly to the cell surface to elicit precise cell responses.

\subsubsection{Bioactive Molecules}

Cell-adhesive molecules such as laminin and fibronectin are utilized in many biofunctionalization strategies owing to their importance in physical axon guidance. Furthermore, their purified or synthesized adhesive domains (Table 22.2) have also been incorporated to improve cell attachment. The advantages associated with immobilizing short peptide motifs, as opposed to the parent protein, includes their enhanced stability during immobilization, affinity for specific ligandreceptor binding because of the reduction of steric hindrance, high density presentation on a substrate, and their ability to target specific cell types and selective signaling pathways. However, the use of whole proteins are often necessary because certain protein functionalities are dependent on structural conformation, which is often lost in purified peptides. 
Table 22.2 List of biologically-active molecules used to biofunctionalize scaffolds in neural tissue engineering, especially for brain repair

\begin{tabular}{|c|c|c|c|}
\hline & & Effects on neuronal cell behavior & References \\
\hline \multirow[t]{4}{*}{$\begin{array}{l}\text { Extracellular } \\
\text { matrix (ECM) } \\
\text { molecules }\end{array}$} & Laminin & $\begin{array}{l}\text { Provides a permissive substrate for } \\
\text { cell and growth cone migration } \\
\text { Enhances neuronal cell adhesion } \\
\text { Promotes and accelerates neurite } \\
\text { outgrowth }\end{array}$ & {$[56,59,74,84,110,116]$} \\
\hline & Collagen & $\begin{array}{l}\text { Structural protein of the ECM } \\
\text { containing specific sites for cell } \\
\text { adhesion, thus enhances cell } \\
\text { attachment }\end{array}$ & [129] \\
\hline & Fibronectin & $\begin{array}{l}\text { ECM protein that promotes cell } \\
\text { adhesion }\end{array}$ & [162] \\
\hline & Vitronectin & $\begin{array}{l}\text { ECM protein that promotes cell } \\
\text { adhesion }\end{array}$ & [17] \\
\hline \multirow[t]{3}{*}{ Peptide motifs } & RGD & $\begin{array}{l}\text { Cell-adhesive peptide sequence } \\
\text { present in many cell-surface receptor } \\
\text { proteins and ECM proteins, including } \\
\text { laminin, fibronectin, and vitronectin }\end{array}$ & {$[31,162]$} \\
\hline & YIGSR & $\begin{array}{l}\text { Peptide sequence within laminin that } \\
\text { enhances neuronal cell adhesion }\end{array}$ & {$[35,55,84,145]$} \\
\hline & IKVAV & $\begin{array}{l}\text { Peptide sequence within laminin that } \\
\text { enhances neurite outgrowth }\end{array}$ & $\begin{array}{l}{[1,30,55,84,124,130,145,} \\
147]\end{array}$ \\
\hline \multirow[t]{3}{*}{ Growth factors } & Nerve growth factor (NGF) & $\begin{array}{l}\text { Critical for neuronal survival during } \\
\text { development and in the adult nervous } \\
\text { systemCan act as a tropic factor, where } \\
\text { neurite outgrowth is guided along the } \\
\text { concentration gradient of NGF }\end{array}$ & {$[19,71,93,133,160]$} \\
\hline & $\begin{array}{l}\text { Brain-derived neurotrophic } \\
\text { factor (BDNF) }\end{array}$ & $\begin{array}{l}\text { Promotes survival of cortical } \\
\text { neuronsImportant for cell survival and } \\
\text { proliferation during } \\
\text { oligodendrogenesis } \\
\text { Promotes NSC proliferation }\end{array}$ & {$[60,83]$} \\
\hline & Neurotrophin-3 (NT-3) & $\begin{array}{l}\text { Promotes neuron survivalEnhances } \\
\text { neurite outgrowth } \\
\text { Can act as a tropic factor, where } \\
\text { neurite outgrowth is guided up the } \\
\text { concentration gradient of NT-3 }\end{array}$ & {$[83,93]$} \\
\hline
\end{tabular}

In addition to adhesive molecules, other biologically-active molecules such as growth factors can be incorporated to target certain cell functions (Table 22.2). In particular, neurotrophins are a family of growth factors that provide target-derived trophic support through receptor-mediated signaling, controlling neuronal outgrowth and connectivity during brain development, and maintenance of neuronal populations in the adult CNS. At different stages of development, neurons depend on more than one neurotrophic factor-receptor signaling pathway to survive. The family of neurotrophins include nerve growth factor (NGF), brain-derived neurotrophic factor (BDNF), neurotrophin-3 (NT-3), and neurotrophin-4 (NT-4). In addition to promoting growth, gradients of neurotrophins are capable of steering the growth cones of primitive and mature neuronal cell types in vitro [60]. Precise control over cell behavior can be achieved by careful manipulation of biomolecular presentation to cells in terms of the type of biomolecule, its conformation, surface density/concentration [89], and spatial patterning. 


\subsubsection{Incorporation of Bioactive Molecules onto Scaffolds}

The main techniques that have been used to incorporate bioactive molecules within scaffolds include blending, physical adsorption, and covalent attachment. Blending involves mixing of biomolecules with the polymer solution during the fabrication process, such that they become physically entrapped within the polymeric structure postfabrication. This is a facile and efficient method of incorporating biomolecules within the bulk and surface of the material at high efficiency. Blending has been used for the introduction of adhesive molecules, such as collagen and laminin, into electrospun nanofibers [74, 129] resulting in improved cell attachment and enhanced neurite outgrowth. For example, the incorporation of collagen into aligned electrospun PCL nanofibers imparts a stronger orientation effect on neurite outgrowth [129]. Blending of neurotrophic factors such as NGF and NT-3 into hydrogels [71,93] is an effective method of guiding neurite outgrowth, and improving cell penetration into poly (2-hydroxyethyl methacrylate) (PHEMA) scaffolds. However, the threshold concentration gradient required to elicit neurite guidance was significantly greater for physically entrapped neurotrophic factors compared to those presented in soluble form. Importantly, when concentration gradients of two immobilized neurotrophic factors, NGF and NT-3, were presented at the same time, the threshold concentration of the individual growth factors required to elicit neurite guidance was lower compared to when growth factors were presented individually, illustrating the synergistic effect of NGF and NT-3 in guiding neurite outgrowth [93]. The spatial distribution of ligands can also partially dictate the effectiveness of a particular protein or peptide motif on cell behavior $[61,89]$.

Bioactive proteins can be physically adsorbed onto a biomaterial surface via nonspecific (noncovalent) bonding. The type of interactions that lead to physical attachment of biomolecules onto the surface can include hydrogen-bonding, hydrophilic or hydrophobic interactions, and electrostatic forces. The bond strength for physically adsorbed molecules is relatively weak; hence, bound molecules are prone to displacement from the surface under in vitro and/or in vivo conditions. Therefore, their biological activity will decrease with time as they diffuse away from the scaffold or become internalized by cells. However, bond strength can be increased by pretreatment of the substrate surface to introduce functional chemical residues, such as carboxyl groups, that enhance physical interaction with the biomolecule. This technique is used predominantly for adsorbing proteins, rather than short peptides, because of stronger interactions between proteins and the material surface. Physically adsorbed adhesive proteins such as laminin are effective in improving cell attachment, proliferation, and neurite outgrowth $[74,112,115,116]$. While physical adsorption presents a simple method of functionalizing surfaces with relevant proteins, it only allows limited control over conformation and exposure of the relevant motif; hence, the resultant bioactivity may not be optimal.

Immobilization of bioactive molecules onto biomaterial surfaces can also be achieved via covalent bonding. Recent studies within our research group have shown that BDNF can be covalently attached onto the surface of electrospun PCL nanofibers. The immobilized BDNFs in combination with the PCL nanofibers were able to enhance adhesion and proliferation of E14.5 cortical progenitor cells, as well as enriching the differentiation of cells into neuronal and oligodendrocyte lineages [59]. Using a similar strategy, Lu not only covalently attached NGF onto the surface of chitosan but were able to control the spatial distribution of the NGF via a photo-patterning method [160]. The chitosan surface was first primed with a bifunctional crosslinker, after which selective surface regions were photo-activated using a UV laser coupled to a confocal microscope to achieve precise spatial control. The concentration of photo-reactive moieties can be manipulated by varying the UV exposure time, which will subsequently determine the concentration of NGF coupled onto the activated surface. Thus, through UV irradiation a gradient pattern of NGF, or other growth factors, can be established. Improvement in cultured superior cervical ganglion cell attachment to the photo-immobilized NGF-patterned chitosan surfaces demonstrated that the NGF was stably bound to the surface, bioactivity was conserved, and that neuronal behavior was dependent on the concentration of NGF presented [160].

Spatial patterning in the form of regular arrays (tracks or squares) [17, 121, 122] of adhesive molecules, and growth factor concentration gradients [1, $34,63,71,72,93$ ] have been used in vitro in an attempt to control cell positioning and direction of process outgrowth. Thus, incorporation of neurotrophic factors 
such as NGF into scaffolds for BTE is an appealing strategy for promoting better neuron survival, differentiation, and directed axonal outgrowth. Morphogens can also be incorporated to help regulate tissue patterning; they display tropic effects where cellular response is dependent on the morphogen concentration. Morphogens that are known to play a role in regulating tissue patterning during development of the nervous system include sonic hedgehog (SHH), Wnt, epidermal growth factor (EGF), fibroblast growth factor (FGF), and transforming growth factor $\beta$ (TGF $\beta$ ) $[3,118]$.

A common technique for patterning $2 \mathrm{D}$ arrays of biomolecules onto substrate surfaces is via microstamping. Micro-stamping involves the use of a microfabricated elastomeric stamp to print regular patterns (e.g., strips) of proteins onto the surface of a substrate. It is commonly used to approximate a continuous gradient by systematically varying the spacing and density of the printed pattern [72]. This involves the "inking" of a prefabricated poly(dimethyl siloxane) (PDMS) stamp in a protein solution, and subsequently physically transferring the protein onto the substrate surface. Microfluidic devices have also been used to generate similar micropatterns, where a microchannel network utilizes laminar flow and diffusive mixing to generate a gradient [72]. The disadvantage of such diffusive gradients is that the it is often not stable over long periods of time, and requires constant replenishment of feeder reservoirs to maintain. Incorporation of biomolecular gradients within such three-dimensional structures have to date only been achieved in hydrogels. However, both approaches have shown promising results in terms of their ability to direct neurite outgrowth toward increasing concentrations of the deposited trophic factor $[19,72,93]$. The ability to generate chemical concentration gradients within 3D scaffold structures, which can also be used in conjunction with structural features, will prove useful for guiding neurite outgrowth. To this end, inkjet printing presents a convenient strategy for not only depositing biomolecules onto 3D scaffolds, but also controlling concentration gradients of biomolecules. These patterning methods can be coupled with the previously described methods of surface immobilization techniques to expose cells to stable concentration gradients.

Self-assembly methods can be used to fabricate biomaterials with a high density of bioactive ligands as well as to have greater control over the peptide conformation. Self-assembled nanofibers consisting of a high density of IKVAV peptides are effective in promoting selective differentiation of mouse NPCs into neurons and supporting long neurite outgrowth in vitro [130], as well as promoting regeneration of motor and sensory nerve fibers of a severed corticospinal tract in vivo [147]. When injected into a damaged mouse spinal cord, the solution of oligopeptides, consisting of the IKVAV peptide amphiphile, resulted in the formation of a self-assembled nanofibrous hydrogel that filled the cavity. This led to an increase in the number of oligodendrocytes surrounding the defect, concurrent with decreased cell death and reduction in scar formation, altogether promoting long-term nerve fiber regeneration within the 11-week study. The effectiveness of the self-assembled nanofibers in promoting nerve regeneration, as compared to the use of the parent protein (laminin) or the peptide sequence tethered to a 2D surface, has been attributed to the amplification of epitope density presented to cells by a factor of approximately $10^{3}$ [130]. Studies into the use of self-assembling peptides for brain repair have been limited, but promising results have been obtained to date [40]. It is envisaged that self assembling peptides will provide excellent scaffolding material in the brain.

\subsubsection{Summary}

Different types of materials with variable microstructures offer a wide degree of flexibility in controlling neuronal regeneration for BTE approaches in controlling neuronal regenerative ability. There are advantages and disadvantages inherent to each type of scaffold that will dictate its efficacy in BTE. One of the main advantages of using in situ gelling hydrogels is the ability to completely fill large cavities and irregular voids, thus creating an intimate interface between host and implant. This type of juxtaposition can be beneficial, but not imperative, for allowing cells from host tissue to enter the highly-hydrated microenvironment. More rigid scaffolds (such as nano- and micro-fibrous scaffolds), which do not conform to lesion cavities the same way as in situ gelling hydrogels, are still able to achieve comparable results in terms of supporting the ingrowth of host tissue as well as survival and growth of seeded cells. It is presumed that such scaffolds act 
as suitable physical and biomolecular templates to trigger tissue regeneration. Regardless of the types of microstructures used, any beneficial effects of scaffold implantation into an injury model involve the ability of the biomaterial to perform the following functions:

- Provide a permissive microenvironment for cell growth and a template to induce appropriate cell architecture

- Avert adverse secondary effects of inflammation that occur naturally in the injured brain (which can be detrimental to the regenerative process), such as infiltration by monocytes and reactive astrocytes, which ultimately leads to scar formations

- Shield new cells from the inhibitory brain microenvironment, while allowing adequate interaction with the host tissue for functional integration

Different fabrication techniques can be used to obtain a variety of morphologies with the capacity to mimic different structural and physiological aspects of the native extracellular microenvironment. Despite these differences, they are able to promote certain cell regenerative events that may ultimately lead to restoration of neuronal pathways, and in the best case, functional recovery. Although surface biofunctionalization strategies can increase the specificity with which cells interact with the scaffold, the importance of scaffold microstructure (e.g., nano-scaled features and microporous structure) in allowing regeneration to occur cannot be understated.

A detailed understanding of the stem cell niche is also very important for BTE as many of the regenerative strategies revolve around mimicking the niche microenvironment to recapitulate developmental events. While advances in nanofabrication techniques have enabled the engineering of more complex, molecularscale, biomimetic scaffold structures, the level of detail and complexity that can be achieved pales in comparison to the natural biological version. Therefore, when undertaking scaffold design for this purpose, such differences and limitations should be considered. It is unreasonable to expect any synthetic/engineered scaffold to fully recapitulate every aspect of the embryonic development process, or the stem cell niche environment. Instead, biological support cells should be harnessed and integrated within the scaffold design to take advantage of their inherent ability to impart certain critical aspects of biological signaling that cannot be otherwise included synthetically.

\subsection{Clinical Application}

Current clinical treatment strategies for brain disorders and injuries are largely limited to cell- or drug-based therapies alone. Drug therapies are primarily aimed at alleviating symptoms or slowing disease progression. However, with the realization of the limited benefits that can be achieved by drug treatment alone, more emphasis is being placed on cell-therapies, with the intention of regenerating cells and their concomitant function(s) lost due to disease or injury.

The treatment strategy will depend on the type and nature of the disorder or injury. The anatomo-pathological features (i.e., whether CNS lesion sites are "focal" or "multifocal") and the types of cells lost will likely dictate the modality of treatment. For example, the focal nature of certain diseases, such as Parkinson's disease (PD) and stroke, makes the direct transplantation of cells into lesion sites a viable strategy for facilitating regeneration. On the contrary, the multifocal nature of neurodegeneration in diseases such as MS and epilepsy means that direct cell transplantation into lesion sites is an impractical approach in assisting regeneration [108]. Therefore, potential clinical treatments to stimulate repair of damage to distinct neural pathways caused by disease or injury will be discussed, using PD as a case study to demonstrate how tissue engineering can bring about a better therapeutic outlook.

\subsubsection{Parkinson's Disease}

PD represents an important case study for strategies used in the regeneration of focal brain lesions because it involves the loss of a distinct cell type (e.g., dopaminergic neurons) and degeneration of highly defined neural pathways. PD is a neurodegenerative disease that is characterized by selective loss of dopaminergic (DA) neurons in the substantia nigra that projects to the striatum in the basal ganglia (Fig. 22.6). The loss of nigrostriatal neurons and subsequent depletion of the neurotransmitter dopamine in the corpus striatum have severe consequence on the control of movement, which typically presents as, but not limited to, bradykinesia (slowed initiation and execution of movements), tremor at rest, cogwheel rigidity (intermittent increase in resistance to passive movement), and postural abnormalities 
Fig. 22.6 Schematic diagram highlighting the degenerate neuronal pathways within the basal ganglia of the brain. Dopamine neurons, with cell bodies located in the substantia nigra, have axonal projections toward to the caudate putamen, where dopamine is released. Selective degeneration of these neurons results in motor symptoms observed in PD-affected patients. Reproduced with permission from Terese Winslow (C2001

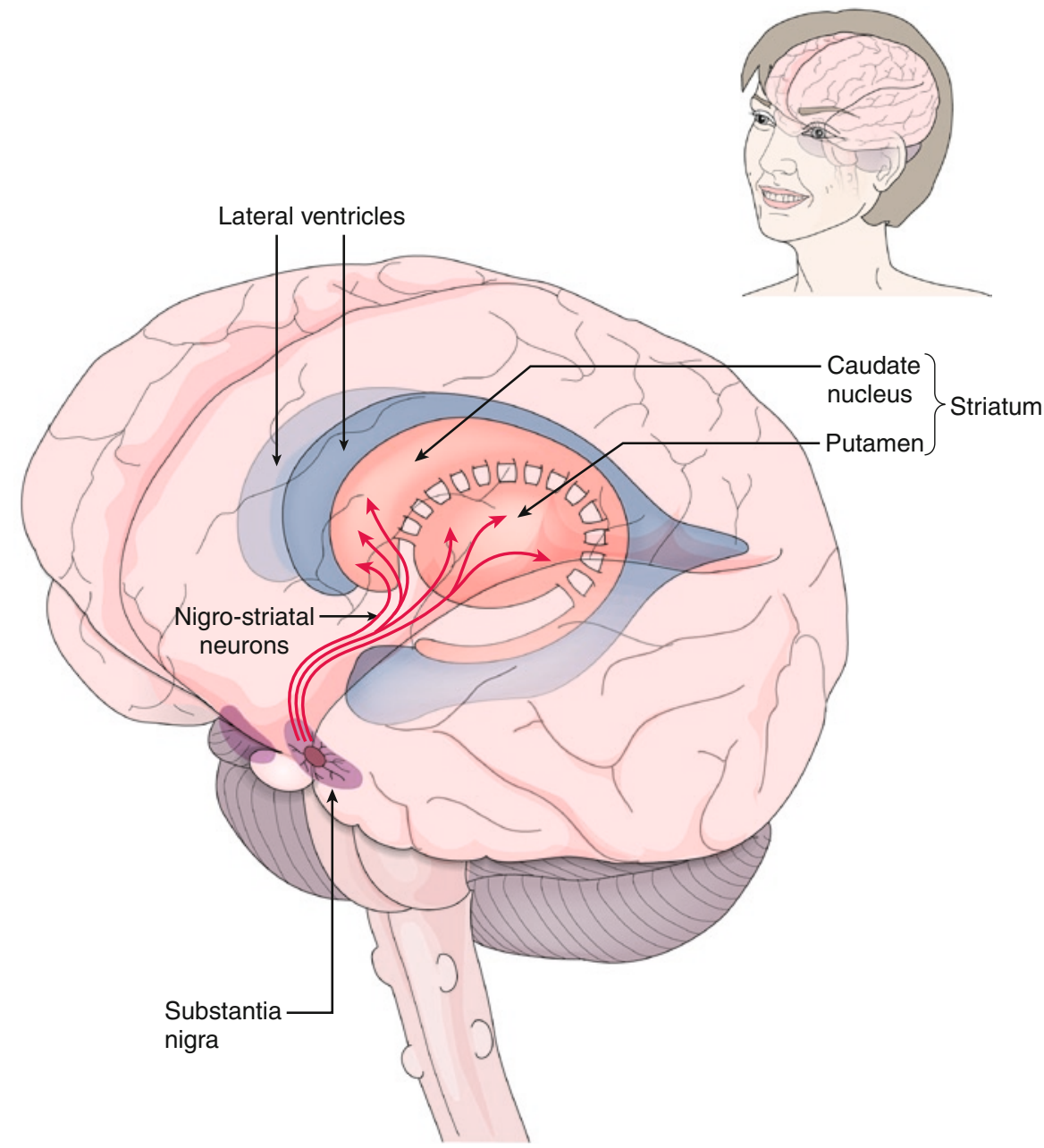

$[90,146]$. The release of dopamine in the striatum is part of a complex feedback loop, where DA inputs from the substantia nigra pars compacta (SNpc) effectively acts to reduce inhibition of thalamocortical neurons, thus facilitating movements initiated in the cortex. Early diagnosis and treatment of PD is often difficult because clinical symptoms only appear when approximately $50 \%$ of the DA neurons in the SNc and $80 \%$ of striatal dopamine are lost [146]. As such, the etiology of the disease still remains elusive, although certain genetic and environmental factors have been implicated in the cause of PD, and appears to involve mitochondrial dysfunction and/or oxidative stress in DA neurons. The presence of Lewy bodies is often viewed as one of the pathological features of PD. Lewy bodies are protein aggregates consisting of $\alpha$-synuclein, neurofilament, crystallin, and proteins of the proteasome [90], which are often used as indicators of disease progression, rather than the cause. The composition of the Lewy bodies has led to the speculation that such inclusions are a reflection of the cell's inability to clear abnormal proteins, which may be an implication of cell dysfunction [90].

The current modalities of therapeutic treatment for PD include pharmacological and surgical approaches. Pharmacological treatment often involves delivery of an exogenous source of dopamine precursors (levodopa or L-DOPA), or dopamine receptor agonists, to alleviate motor symptoms brought about by the dopamine deficiency in the striatum [90, 146]. However, drug treatment strategies only provide limited relief of motor symptoms, and the beneficial effects often wear off after approximately 5 years, as patients become refractory to the effects of dopamine 
treatment $[15,146]$. Surgical therapy is an alternative treatment modality that aims to relieve motor symptoms by destruction (via surgical ablation or electrical stimulation) of specific deep brain structures to remove pathways that are partially responsible for the aberrant signaling [146]. These two types of treatment modalities only have limited efficacy in terms of the extent and duration of symptomatic relief that they can offer, and are often associated with many severe side effects. More importantly, at best, these are purely symptomatic treatments that are incapable of stopping, or reverting the course of the disease, and they cannot restore the loss of function incurred.

Cell-based therapies were developed as a potential long-term treatment for PD that aims to replace the DA neurons lost to the degenerative disease. Direct transplantation of fetal midbrain tissue (consisting of DA neurons) into preclinical models of PD had shown great promise, where the transplanted cells were able to reinnervate the damaged striatum, leading to significant functional (motor) recovery [10, 11, 81, 128]. Despite such promising results in preclinical studies, the results of clinical trials in which human fetal mesencephalic tissue was transplanted into the brains of PD patients have been mixed [44, 75, 80, 92, 103]. While cell replacement therapies appear to bring about short-term improvement of motor symptoms, there is scarce evidence for the long-term benefits of cell transplantation both clinically and in post-mortem analysis of the brain. It has been postulated that the limited efficacy may be partially due to the crude tissue preparation that consists of a heterogeneous population of cells, of which only approximately $10 \%$ are DA neurons $[18,152]$. Axonal projections of transplanted DA neurons have been shown to make appropriate connections with target cells in the striatum, but the dendritic spines often do not receive input from its natural targets. This results in the unregulated release of dopamine from the transplanted DA neurons, as well as inappropriate release of serotonin from other cells present in the transplant $[90,92]$. Significantly, recent postmortem analysis of some PD patients, who had survived the transplantation for more than 10 years, shows that the grafted neurons also developed Lewy body pathology $[75,80]$. This provides strong evidence that grafted cells can also become affected by the PD pathology through prolonged interaction with the diseased host tissue. There is also strong evidence that neuronal degeneration in PD is not limited to DA neurons in the nigrostriatal pathway, but is also seen in neurons within the corticostriatal and thalamostriatal pathways at different stages of the disease [16, 137]. Thus, therapy based on restoration of the nigrostriatal pathway alone is likely to provide only temporary relief of motor symptoms, albeit longer than both drug and surgical therapy. As the related pathways and cell types that are affected in PD become elucidated, and more updated models describing PD progression are developed [16], it becomes apparent that effective treatment strategies must take into account the widespread degeneration of neurons in other parts of the nervous system.

While restoration of the nigrostriatal pathways may not provide a cure for PD, it is likely to remain a major component in the ultimate treatment regime. Therefore, current limitations to cell-based therapies, namely poor viability (only 3-5\% of surviving transplanted cells are DA neurons, representing approximately $0.3 \%$ of total grafted cells $[106,139])$ and heterogeneous nature of transplanted fetal tissue, must be addressed. Cell replacement therapies require fetal midbrain tissue to be obtained from multiple (up to 6-8) embryos and cell expansion in culture to reach therapeutically relevant quantities [82, 104, 146]. In addition, implanted fetal midbrain cells have poor viability, which in combination with the low percentage of relevant cell types in the transplanted tissue, further limits the efficiency of such cell-based therapies. Various tissue-engineered scaffolds, in particular hydrogels, appear capable of alleviating such limitations by providing a permissive environment for cell survival in vivo. Issues such as ectopic termination of dendritic and axonal processes, and persistence of irrelevant cell types, both of which are active topics of research in BTE, can be potentially resolved through the use of well-designed scaffolds and stem/progenitor cells. Physical and biochemical cues can be embedded within the scaffold to direct differentiation of exogenous stem cells into DA neurons, as well as guide process outgrowth such that the nigrostriatal pathway can be reconstructed.

Because of their capacity for self-renewal and differentiation into multiple cell types, stem cells have been heavily studied for use in cell replacement strategies. However, the differentiation of stem cells into a stable DA phenotype, even under the relatively stable in vitro conditions, is not a trivial task; as such there is still much debate regarding the type of stem cells 
(embryonic or neural), and the state of differentiation of cells to be used for transplantation. Transplanted ESCs have shown a propensity to develop into teratomas [12, 135], whereas transplantation of differentiated DA neurons results in poor survival and subooptimal integration in the host brain [75, 76, 80, 91, 92]. Tissue engineering principles can be applied by combining a suitable scaffold, stem cells, and appropriate signaling molecules to improve clinical outcomes. In essence, the scaffold will function to improve the cell viability during the transplantation procedure by presenting a permissive microenvironment for cellular growth, while also shielding cells from any external inhibitory conditions. Such a scaffold can also be tailored with bioactive functionalities to meet the following objectives:

- Promote cell proliferation to generate an adequately large population to replace the cells lost to the degenerative process

- Specifically direct cell differentiation to attain relevant cell types only (i.e., DA neurons)

- Direct both axonal and dendritic processes to make connections with the appropriate cell types within the host brain

Optimization of each of these scaffold components is still required. However, the prospect of implanting such a scaffold directly into the lesion site of PD patients to bring about greater long-term relief from motor symptoms awaits further studies in vivo. The same principles can be adapted to regenerate other pathways that are known to be affected by PD.

\subsubsection{Summary}

For many brain disorders, such as PD and MS, the ultimate cause is mostly undetermined, which presents limitations to the effectiveness of any treatment aimed at alleviating symptoms, restoring function, and eventually curing the disease. Without an understanding of the upstream cellular dysfunctions, treatment downstream of the disease origin will provide limited relief of symptoms only. Nevertheless, because of the debilitating nature of any disorders of the brain, any partial relief that can be achieved will bring about significant benefits for the patient. Current existing treatments for CNS disorders revolve around drug therapy, surgical treatment, and cellbased therapy. Cell-replacement therapies are receiving greater attention with the expectation of regaining lost functions via restoration of affected cellular pathways. To this end, tissue engineering holds the potential to provide treatments that are superior to any of the currently existing treatment strategies. This potential lies in the capacity to approach treatment strategies in a more targeted and delicate manner, achieving regeneration or symptomatic relief with greater efficiency and fewer side effects. With the abundance of tools available for tailoring scaffolds with specific physical, structural, and biochemical properties, and the selection of stem/progenitor cells, a logically designed scaffold can be custom-made for individual patients with particular disorders. Thus, it is envisioned that tissue engineering principles will provide improved treatment strategies for various disorders of the brain.

\subsection{Expert Opinion}

\subsubsection{Challenges in Tissue Engineering for Brain Repair}

Tissue engineering in the brain requires a highly complex and multidisciplinary set of skills. The development of a single scaffold and cell therapy for this purpose can draw upon many fields including computational and experimental neurosciences, stem cell biology, clinical neurology, electrical engineering and signal propagation, materials engineering, nanotechnology, and surface science to name a few. Overall, the common goal is to restore physiological brain function through facilitating appropriate interactions between the CNS and the scaffolds developed for this purpose.

Recently, there has been considerable progress made toward understanding the barriers to regeneration within the adult mammalian brain, as well as different mechanisms that allow for regeneration and function recovery. These advances have paved the way for many different therapeutic avenues, including BTE. However, the recent progress toward axonal regeneration in vivo has mainly been restricted to the PNS using autografts, allografts, and xenografts. For nerve regeneration in the PNS, autografts are considered to be the best form of clinical treatment, as there is no need for immunosuppressive therapy post surgery. However, such strategies are problematic and impractical in the brain. 
Any scaffold used to repair damaged tissue within the brain must not exacerbate the innate inflammatory response, or any appreciable form of FBR or cytotoxic response. In addition, the mechanical properties of the scaffolds should have a modulus similar to that of the surrounding tissue not only to avoid structural collapse during normal human activities but also to limit local tearing of surrounding tissue. Recently, considerable progress has been made toward generating biocompatible and compliance-matched biomaterials for nerve regeneration $[6,27,48,59,68,151]$. However, in addition to these requirements it is also ideal for BTE scaffolds to have a porous structure and be biodegradable under physiological conditions. Ideal scaffolds will also have major roles in the following areas:

- Presenting cell adhesion and signaling molecules

- Delivering or presenting growth factors at specific stages of the regeneration process

- Incorporation of different support cells while facilitating their viability and migration

Fundamentally, the incorporation of all of these requirements into a single scaffold represents the holy grail for BTE, as it would replicate steps present during CNS development by providing a physical and biochemical platform for regeneration to occur, which would otherwise be absent or suppressed in the adult mammalian nervous system. Such regeneration would also require long-term histological analysis in preclinical models to determine structural integrity of repair sites, as well as functional repair using local innervations studies or whole animal scanning modalities. Once such regeneration is achieved, it will be critical for the patient to undergo extensive rehabilitation to facilitate adequate signal transduction down the regenerated pathways and synaptic remodeling before symptoms can be fully eradicated.

To date, despite extensive research, scaffolds or conduits only have the ability to incorporate several, but not all, of these critical requirements; hence, efficient and effective brain regeneration remains on the horizon.

\subsubsection{Current and Future Scaffolds for Brain Repair}

Recent efforts have focused on the formation of scaffolds that are designed to guide axonal regeneration from one location to another. These can be produced from a variety of different techniques, but thus far the majority of research has focused on electrospun and hydrogel scaffolds.

Electrospun polymer nanofibers have shown considerable promise because they provide the nano-dimension necessary for intimate interactions between regenerating brain tissue and the 3D environment provided by the scaffold. Neurites, as nano-scaled structures, extend parallel to the fiber direction when cultured on aligned nanofibers, inferring that contact guidance is providing a dominant cue for directing regeneration. However, a greater understanding of the interplay between physical and chemical cues will be essential for the progression of nerve regeneration within the brain.

Both synthetic and natural hydrogels have also shown considerable promise for nerve regeneration. They can be engineered to exhibit a thermo-responsive character and can be easily injected, and chemically modified to present desired growth factors to neuronal cells. One of the disadvantages of using hydrogels is that they are isotropic structures and therefore unable to provide directional cues. Consequently, exogenous delivery of neurotrophic factors, either homogeneously or as an immobilized gradient, is often required; however, such modified hydrogels have had limited success for neuronal regeneration over large distances.

The fabrication of a scaffold that simulates some features of the $3 \mathrm{D}$ niche is important to support the maintenance of implanted stem/progenitor cells. The scaffold must also provide guidance cues for the regenerating axon to reach its target and to control the relative positions of neurons and glia. It is already apparent that the characteristics needed to meet these two requirements are probably mutually exclusive. Thus, the use of multiphase scaffolds appears to be the next logical progression in scaffold design for BTE. For example, electrospun nanofibers with layered architectures of both aligned (providing contact guidance and controlling cell migration) and randomly orientated nanofibers (providing stem cell niches) can be envisaged. Different designs that consist of a mixture of composite material and microstructure, for instance incorporating aligned nanofibres within an isotropic hydrogel, in combination with biochemical support for regenerating axons may be more appropriate than current designs. Such biochemical support may be offered by growth factors (either soluble or immobilized to the fibers/hydrogel), and cellular support provided by stem cells and glial cells to the endogenous 
tissue. However, the major pitfall of the use of guidance channels in the brain, as in the case of autografts, is the invasive surgical techniques that are required for implantation.

Current trends in surface micro- and nanotechnology are beginning to explore alternative methods of surface structuring at the cellular scale. To this end, inkjet printing of biomolecules, or even cells, represents a unique and high-throughput method, which may prove to be more economically viable and timesaving than soft lithographic approaches. Similar to the previously described micro-patterning techniques, spatial organization of cells can be achieved by inkjet printing of biomolecular patterns on a cell nonadhesive background [63, 120, 123]. Alternatively, cells can be directly deposited onto predetermined positions on the scaffolds via inkjet printing $[13,14,117,125,155$, 156]. Primary embryonic rat motoneurons, as well as hippocampal and cortical cells that were deposited by inkjet printing not only survived the printing process, but also exhibited typical neuronal morphology and electrophysiological characteristics $[155,156]$.

In addition to controlling cell positioning within a scaffold, inkjet printing can be used as another method of depositing concentration gradients of chemotropic factors and presenting chemotactic cues to direct cell migration and neurite outgrowth. Inkjet printed gradients approximate truly continuous gradients via the use of halftones, by varying the size and spacing between deposited droplets. Current commercial inkjet printers are capable of delivering drop sizes as small as 1-5 pL, producing spot sizes on substrates of approximately $20 \mu \mathrm{m}$ [77]. Given that a typical growth cone has a radius of approximately $10 \mu \mathrm{m}$, and estimated concentration gradients generated via inkjet printing can have a resolution in the order of $10 \mu \mathrm{m}$, inkjet printed gradients should have sufficiently high resolution for directing neurite outgrowth especially with short range neurotrophins.

All equipment and components for inkjet printing are inexpensive and commercially available, and can be modified with relative ease to accommodate specific printing systems. Thus, inkjet printing has been used to print micro- and nano-arrays of proteins, nucleic acids, and even cells [63, 102, 119, 120, 125, 155, 156]. Despite exposure to high temperatures and high shear rate during the printing process, printed cells can remain viable, and printed proteins can remain bioactive. For example, a modified thermal inkjet printer has been used to print concentration gradients of fibroblast growth factor-2 (FGF-2) and ciliary neurotrophic factor (CNTF) onto thin films of polyacrylamide-based hydrogels. FGF-2 was used to maintain NSCs in a proliferative progenitor state, while CNTF was used to induce rapid differentiation of NSCs into astrocytes. Although concentration gradients of these factors were approximated by varying drop density, NSCs cultured on the printed gradients of CNTF demonstrated a linear increase in number of astrocytes. In thermal inkjet printing, the timescales involved in the drop ejection process (in the order of $100 \mu \mathrm{s}$ ) are sufficiently small to limit the diffusion of heat to the bulk of the liquid [156]. Therefore, it is possible that the majority of printed proteins will not be denatured because of the elevated temperatures associated with thermal inkjet printing.

\subsection{Five-Year Perspective}

While the long term aim of BTE strategies is brain repair, there are some intermediate goals that need to be more thoroughly understood before the ultimate aim can be realized. The molecular, cellular, and structural processes that guide the formation of white matter (axonal tracts) and grey matter (cell bodies), and the manner in which neurons and neurites assemble into interconnected communication channels, as well as the timing of these events must be considered in their entirety. Biologically, all these occur in 3D, yet in most circumstances these processes have been studied in vitro using 2D cell cultures, because of technical hurdles in modeling the complexity of the brain for long periods. Therefore, an immediate aim should be to develop scaffolds that can better integrate in vitro cell culture models, explants, or organotypic models, with in vivo animal models to address the current pitfalls that exist for cell replacement therapies and in vivo axonal extension. To this end, the already multipldiciplinary field must further expand and develop its interdisciplinary skills to produce structural and functional nano-materials that will encourage the formation of nuclei and neuronal tracts in 3D.

Such 3D culture tools would allow for a greater understanding with regard to the interactions between cells and their physical environment, while also offering some insight into chemical cues (signaling 
molecules) and how they organize white matter tract and nuclei formation. For instance, the ability to manipulate important biological processes such as contact guidance, cell-cell interaction, and chemotaxis, to achieve meaningful outcomes in BTE is not yet fully understood. Three-dimensional culture tools may prove critical in answering these fundamental questions. In the next 5 years, these studies are vital in order to gain an understanding of the normal function and repair processes within the adult mammalian brain.

It follows that the critical criteria for developing a scaffold aimed at mimicking features of the natural ECM for brain repair must satisfy the following requirements:

- Provide discrete 3D niche environments that can selectively promote either cell body or neuronal tract formation

- Enable determination of the relative contributions of trophic factors, physical factors, and cell-cell interactions in inducing axon guidance

- Work toward an understanding of the temporal nature of chemical signals in tract formation

$3 \mathrm{D}$ in vitro models are essential to study the complex interplay of the ECM environment, including chemical and mechanical stimulation, with cells. To achieve this, the next generation of nano-biomaterials should replicate the multifaceted features of the native 3D cellular niche. Recently, it has been shown that neurons cultured on $3 \mathrm{D}$ nanofibers or hydrogels adopt more in vivo-like morphologies compared to cultures on 2D substrates of the same material [99], highlighting the importance of providing architectural features that are similar to the native ECM. Furthermore, mechanical stimulus (e.g., substrate elasticity) can influence focal-adhesions and cytoskeletal organization, and has been shown to be a powerful regulator of stem cell differentiation. Substrate elasticity in 2D formats can also influence neurite outgrowth; hence, the optimization of this parameter for tissue engineering within the brain is also relevant. It is likely that the ability of cells to sense substrate stiffness in a 3D environment will be highly relevant to the final outcome of neuronal regeneration. Even though its effects remain largely unknown, the optimized combination and synergies of elasticity and 3D architecture may prove to be a dominant and powerful regulator of neuronal expression.

\subsection{Limitations/Critical Review}

Despite promising progress in our understanding of both molecular and cellular mechanisms underpinning development, regeneration, and disease processes, translation of tissue engineering principles into the clinical setting remains a challenge. One of the main issues that limit self-repair mechanisms within the brain following disease and injury is the naturally inhibitory CNS environment. In addition to this inhibitory environment, the presence of highly confined neurogenic niches may represent an evolutionary mechanism that reflects the importance of maintaining stable "hard-wired" neuronal networks for normal adult brain function. Excessive growth and introduction of new neurons into highly precise, existing circuits may interfere with brain function. While suppression of such (neurogenic) events is essential in a healthy brain, it poses severe limitations for brain tissue remodeling and regeneration in response to disease and injury. Indeed, therapeutic suppression of a natural and neuroprotective immune response may be detrimental, by prolonging a chronic state of disrepair that may lead to long term sideeffects.

Tissue engineering in the brain strives to restore normal brain function following disease or injury by enabling cells to regenerate and reform any lost connections. The general approach to this problem involves the use of an optimized combination of scaffold, exogenous source of cells, and signaling molecules to recreate an environment with the capacity to trigger a sequence of cellular events that promote regeneration. However, interactions between cells and their natural extracellular environment are highly complex, where cells receive and integrate an intricate sequence of information from multiple sources (ECM, nearby cells, distant cells, growth factors), as well as routine signaling during normal neural circuit processes. It appears that the spatial and temporal coordination of signaling events provides multiple opportunities for modulation and fine control of cell response, while maintaining robustness and preservation of tissue function. This level of complexity is very hard to mimic, and detailed studies of the temporal, spatial, and cellular (phenotype) evolution of signaling events are required to elicit appropriate cellular responses such as proliferation, migration, and differentiation. 
Traditional cell replacement therapies utilized in degenerative diseases such as PD are often viewed as a crude approach in addressing a meticulous problem of restoring neuronal circuitry. They highlight the advantages of engaging tissue engineering approaches to achieve greater efficacy in treatment of brain disorders because of their potential ability to precisely control cell behavior both before and after implantation. This ultimately means that transplanted cells will have a better chance of achieving functional integration into the existing host circuitry. However, in order for tissue-engineering based treatments to become prominent in the clinical setting, the longterm performance of therapeutic interventions using scaffold-based approaches need to be established. Many in vivo studies have often shown that the observed restoration of degenerated neuronal pathway does not always correlate to the degree of functional recovery. Therefore, the link between local brain regeneration and improvement in clinical outcomes needs to be further investigated. It is equally important in the development of repair and regeneration strategies to consider the cause/etiology of a disease, and not just to focus on replacing cells lost as part of the disease process.

\subsection{Conclusion/Summary}

The primary requirement of any scaffolds for tissue engineering is to provide a permissive environment that is conducive to cell growth and survival. Thereafter, BTE places significant emphasis on recreating a specialized niche microenvironment endowed with physical, biochemical, and biological cues to instruct cell behavior. While an arsenal of techniques have been developed to control various aspects of cell behavior - including survival, adhesion, proliferation, migration, differentiation, and process outgrowth the precise mechanisms via which individual cues exert influences over cell behavior are still being uncovered, and the optimal combinations and possible synergy that can be achieved through a combination of BTE interventions are still also evolving in parallel with these new biological insights.

Even though the design of synthetic scaffolds should endeavor to replicate certain conditions that occur during embryonic brain development, recapitulation of all such cellular events is both impractical and not necessarily required for regeneration to occur. However, it is anticipated that scaffolds utilized for BTE should embrace the concept of biomolecular signal presentation to cells in a spatially and temporally coordinated manner, with a concomitant sequence of cellular responses.

Of the currently available fabrication technologies, hydrogels, electrospun and self-assembled nanofibers to exhibit desirable architectural and structural features to support cell adhesion and survival. Properties of the electrospun scaffolds, such as average fiber diameter, fiber alignment, and interfiber distance can be systematically altered to modulate various aspects of cell behavior. However, progress in BTE is likely to require innovative designs, combining elements of different scaffolds that are known to promote desirable cell behavior. The use of scaffolds with component structures that are optimized for different cell behaviors (e.g., neurite outgrowth and supportive niche conditions) is likely to become an important next step in BTE. Biofunctionalization of scaffolds with growth factors, adhesive ECM proteins, and peptide motifs has also become a prerequisite for selectively enhancing cell response through specific and ordered ligandreceptor mediated signaling cascades. The importance of biological support cells within scaffolds is also becoming more apparent, improving interaction between cells and the substrates, as well as providing a biochemical milieu that is required for cellular regeneration, which cannot be generated by synthetic means.

In order for more effective therapeutic treatments to be developed, a comprehensive understanding of the roles and interactions of cells and bioactive molecules in the normal and diseased brain needs to be elucidated. Of particular importance is how neurogenesis and gliogenesis are regulated in the adult brain and how they can be harnessed in the regeneration process via tissue engineering principles. This includes an improved understanding of the significance and functions of different cell types, as well as cells in different stages of their developmental program. It is hoped that the wealth of technical expertise in the fabrication of biomaterial scaffolds for BTE will continue to mesh synergistically with stem cell and regenerative medicine, and resources from existing therapies, to expedite bench-to-bedside efforts for brain repair. 


\section{Suggested Readings}

Boland T, Tao X, Damon B, et al. Application of inkjet printing to tissue engineering. Biotechnol J. 2006;1:910-7.

Cui FZ, Tian WM, Hou SP, et al. Hyaluronic acid hydrogel immobilized with RGD peptides for brain tissue engineering. J Mater Sci: Mater Med. 2006;17:1393-401.

Ellis-Behnke RG, Liang Y-X, You S-W, et al. Nano neuro knitting: peptide nanofiber scaffold for brain repair and axon regeneration with functional return of vision. PNAS. 2006;103: 5054-9.

Engler AJ, Sen S, Sweeney HL, et al. Matrix elasticity directs stem cell lineage specification. Cell. 2006;126:677-89.

Huang EJ, Reichardt LF. Neurotrophins: roles in neuronal development and function. Annu Rev Neurosci. 2001;24: 677-736.

Hubbell JA. Bioactive biomaterials. Curr Opin Biotechnol. 1999;10(2):123-9.

Mahoney MJ, Anseth KS. Three-dimensional growth and function of neural tissue in degradable polyethylene glycol hydrogels. Biomaterials. 2006;27:2265-74.

Martino G, Pluchino S. The therapeutic potential of neural stem cells. Nat Rev Neurosci. 2006;7(5):395-406.

Moore K, Macsween M, Shoichet MS. Immobilized concentration gradients of neurotrophic factors guide neurite outgrowth of primary neurons in macroporous scaffolds. Tissue Eng. 2006;12(2):267-78.

Nisbet DR, Crompton KE, Horne MK, et al. Neural tissue engineering of the CNS using hydrogels. J Biomed Mater Res B Appl Biomater. 2008;87B(1):251-63.

Nisbet DR, Forsythe JS, Shen W, et al. Review paper: a review of the cellular response on electrospun nanofibers for tissue engineering. J Biomater Appl. 2008;87:251-63.

Parish CL, Arenas E. Stem-cell-based strategies for the treatment of Parkinson's disease. Neurodegenerative Dis. 2007; 4:339-47.

Riquelme PA, Drapeau E, Doetsch F. Brain micro-ecologies: neural stem cell niches in the adult mammalian brain. Phil Trans R Soc B. 2008;363:123-37.

Sofroniew MV. Reactive astrocytes in neural repair and protection. Neuroscientist. 2005;11(5):400-7.

West JL, Hubbell JA. Polymeric biomaterials with degradation sites for proteases involved in cell migration. Macromolecules. 1999;32(1):241-4.

Yu LMY, Wosnick JH, Shoichet MS. Miniaturized system of neurotrophin patterning for guided regeneration. J Neurosci Methods. 2008;171:253-63.

Zhang S. Fabrication of novel biomaterials through molecular self-assembly. Nat Biotech. 2003;21(10):1171-8.

\section{References}

1. Adams DN, Kao EYC, Hypolite CL, et al. Growth cones turn and migrate up an immobilized gradient of the laminin IKVAV peptide. J Neurobiol. 2004;62:134-47.

2. Aloisi F. Immune function of microglia. Glia. 2001; 36:165-79.
3. Alvarez-Buylla A, Lim DA. For the long run: maintaining germinal niches in the adult brain. Neuron. 2004;41(5): 683-6.

4. Alvarez-Buylla A, Temple S. Stem cells in the developing and adult nervous system. J Neurobiol. 1998;36(2): 105-10.

5. Anderson RB, Key B. Novel guidance cues during neuronal pathfinding in the early scaffold of axon tracts in the rostral brain. Development. 1999;126(9):1859-68.

6. Balgude AP, Yu X, Szymanski A, et al. Agarose gel stiffness determines rate of DRG neurite extension in $3 \mathrm{D}$ cultures. Biomaterials. 2001;22:1077-84.

7. Batchelor PE, Howells DW. CNS regeneration: clinical possibility or basic science fantasy? J Clin Neurosci. 2003; 10(5):523-34.

8. Bertrand N, Castro DS, Guillemot F. Proneural genes and the specification of neural cell types. Nat Rev Neurosci. 2002;3(7):517-30.

9. Biran R, Noble MD, Tresco PA. Directed nerve outgrowth is enhanced by engineered glial substrates. Exp Neurol. 2003;184(1):141-52.

10. Björklund A, Dunnett SB, Stenevi U, et al. Reinnervation of the denervated striatum by substantia nigra transplants: functional consequences as revealed by pharmacological and sensorimotor testing. Brain Res. 1980;199(2): 307-33.

11. Björklund A, Stenevi U. Reconstruction of the nigrostriatal dopamine pathway by intracerebral nigral transplants. Brain Res. 1979;177(3):555-60.

12. Bjorklund LM, Sanchez-Pernaute R, Chung S, et al. Embryonic stem cells develop into functional dopaminergic neurons after transplantation in a Parkinson rat model. Proc Natl Acad Sci. 2002;99:2344-9.

13. Boland T, Mironov V, Gutowska A, et al. Cell and organ printing 2: fusion of cell aggregates in three-dimensional gels. Anat Rec A Discov Mol Cell Evol Biol. 2003; 272:497-502.

14. Boland T, Tao X, Damon B, et al. Application of inkjet printing to tissue engineering. Biotechnol J. 2006;1:910-7.

15. Braak H, Del Tredici K. Assessing fetal nerve cell grafts in Parkinson's disease. Nat Med. 2008;14(5):483-5.

16. Braak H, Del Tredici K. Cortico-basal ganglia-cortical circuitry in Parkinson's disease reconsidered. Exp Neurol. 2008;212(1):226-9.

17. Britland S, Perridge C, Denyer M, et al. Morphogenetic guidance cues can interact synergistically and hierarchically in steering nerve cell growth. Exp Biol Online. 1996; $1(2): 1-15$.

18. Brundin P, Isacson $\mathrm{O}$, Gage $\mathrm{FH}$, et al. Intrastriatal grafting of dopamine-containing neuronal cell suspensions: effects of mixing with target or non-target cells. Brain Res. 1986; 389:77-84.

19. Cao X, Shoichet MS. Defining the concentration gradient of nerve growth factor for guided neurite outgrowth. Neuroscience. 2001;103(3):831-40.

20. Carleton A, Petreanu LT, Lansford R, et al. Becoming a new neuron in the adult olfactory bulb. Nat Neurosci. 2003; 6:507-18.

21. Cheng M, Deng J, Yang F, et al. Study on physical properties and nerve cell affinity of composite films from chitosan and gelatin solutions. Biomaterials. 2003;24(17):2871-80. 
22. Cheng S, Clarke EC, Bilston LE. Rheological properties of the tissues of the central nervous system: a review. Med Eng Phys. 2008;30(10):1318-37.

23. Chew SY, Mi R, Hoke A, et al. Aligned protein-polymer composite fibers enhance nerve regeneration: a potential tissue-engineering platform. Adv Funct Mater. 2007; 17:1288-96.

24. Chew SY, Mi R, Hoke A, et al. The effect of the alignment of electrospun fibrous scaffolds on schwann cell maturation. Biomaterials. 2008;29:653-61.

25. Chew SY, Mi R, Hoke A, et al. The effect of the alignment of electrospun fibrous scaffolds on schwann cell maturation. Biomaterials. 2008;29:653-61.

26. Christopherson GT, Song H, Mao H-Q. The influence of fiber diameter of electrospun substrates on neural stem cell differentiation and proliferation. Biomaterials. 2009;30(4): 556-64.

27. Crompton KE, Goud JD, Bellamkonda RV, et al. Polylysinefunctionalized thermoresponsive chitosan hydrogel for neural tissue engineering. Biomaterials. 2007;28:441-9.

28. Crompton KE, Prankerd RJ, Paganin DM, et al. Morphology and gelation of thermosensitive chitosan hydrogels. Biophys Chem. 2005; 117:45-53.

29. Crompton KE, Tomas D, Finkelstein DI, et al. Inflammatory response on injection of chitosan/GP to the brain. J Mater Sci Mater Med. 2006;17:633-9.

30. Cui FZ, Tian WM, Fan YW, et al. Cerebrum repair with PHPMA hydrogel immobilized with neurite-promoting peptides in traumatic brain injury of adult rat model. J Bioact Compat Polym. 2003;18(6):413-32.

31. Cui FZ, Tian WM, Hou SP, et al. Hyaluronic acid hydrogel immobilized with RGD peptides for brain tissue engineering. J Mater Sci Mater Med. 2006;17:1393-401.

32. Dalton PD, Klee D, Moller M. Electrospinning with dual collection rings. Polymer. 2005;46:611-4.

33. Debellard M-E, Tang S, Mukhopadhyay G, et al. Myelinassociated glycoprotein inhibits axonal regeneration from a variety of neurons via interaction with a sialoglycoprotein. Mol Cell Neurosci. 1996;7(2):89-101.

34. Dertinger SKW, Jiang X, Li Z, et al. Gradients of substratebound laminin orient axonal specifications of neurons. Proc Natl Acad Sci. 2002;99(20):12542-7.

35. Dhoot NO, Tobias CA, Fischer I, et al. Peptide-modified alginate surfaces as a growth permissive substrate for neurite outgrowth. J Biomed Mater Res A. 2004;71A(2): 191-200.

36. Dickson BJ. Molecular mechanisms of axon guidance. Science. 2002;298:1959-64.

37. Doetsch F. A niche for adult neural stem cells. Curr Opin Genet Dev. 2003;13(5):543-50.

38. Duconseille E, Carrot S-N, Woerly S, et al. Homotopic grafts of septal neurons combined to polymeric hydrogels placed into a fimbria-fornix lesion cavity attenuate locomotor hyperactivity but not mnemonic dysfunctions in rats. Restor Neurol Neurosci. 2001;18:39-51.

39. Duconseille E, Woerly S, Kelche C, et al. Polymeric hydrogels placed into a fimbria-fornix lesion cavity promote fiber (re)growth: a morphological study in the rat. Restor Neurol Neurosci. 1998;13:193-203.

40. Ellis-Behnke RG, Liang Y-X, You S-W, et al. Nano neuro knitting: peptide nanofiber scaffold for brain repair and axon regeneration with functional return of vision. Proc Natl Acad Sci. 2006;103:5054-9.

41. Engler AJ, Sen S, Sweeney HL, et al. Matrix elasticity directs stem cell lineage specification. Cell. 2006;126: 677-89.

42. Faulkner JR, Herrmann JE, Woo MJ, et al. Reactive astrocytes protect tissue and preserve function after spinal cord injury. J Neurosci. 2004;24(9):2143-55.

43. Flanagan LA, Ju Y-E, Marg B, et al. Neurite branching on deformable substrates. Neuroreport. 2002;13(18): 2411-5.

44. Freed CR, Greene PE, Breeze RE, et al. Transplantation of embryonic dopamine neurons for severe Parkinson's disease. N Engl J Med. 2001;344(10):710-9.

45. Gage FH. Mammalian neural stem cells. Science. 2000;287(5457):1433-8.

46. Gage FH, Kempermann G, Palmer TD, et al. Multipotent progenitor cells in the adult dentate gyrus. J Neurobiol. 1998;36(2):249-66.

47. Gehrmann J, Matsumoto Y, Kreutzberg GW. Microglia: intrinsic immuneffector cell of the brain. Brain Res Rev. 1995;20(3):269-87.

48. Georges PC, Miller WJ, Meaney DF, et al. Matrices with compliance comparable to that of brain tissue select neuronal over glial growth in mixed cortical cultures. Biophys J. 2006;90:3012-8.

49. Gerecht S, Burdick JA, Ferreira LS, et al. Hyaluronic acid hydrogel for controlled self-renewal and differentiation of human embryonic stem cells. Proc Natl Acad Sci. 2007; 104(27):11298-303.

50. Ghasemi-Mobarakeh L, Prabhakaran MP, Morshed M, et al. Electrospun poly(caprolactone)/gelatin nanofibrous scaffolds for nerve tissue engineering. Biomaterials. 2008;29(34): 4532-9.

51. Glezer I, Simard AR, Rivest S. Neuroprotective role of the innate immune system by microglia. Neuroscience. 2007; 147(4):867-83.

52. Gong HP, Zhong YH, Li JC, et al. Studies on nerve cell affinity of chitosan-derived materials. J Biomed Mater Res. 2000;52:285.

53. Green M, Bilston L, Sinkus R. In vivo brain viscoelastic properties measured by magnetic resonance elastography. NMR Biomed. 2008;21:755-64.

54. Hamhaber U, Sack I, Papazoglou S, et al. Three-dimensional analysis of shear wave propagation observed by in vivo magnetic resonance elastography of the brain. Acta Biomater. 2007;3(1):27-37.

55. He L, Liao S, Quan D, et al. The influence of laminin-derived peptides conjugated to Lys-capped PLLA on neonatal mouse cerebellum C17.2 stem cells. Biomaterials. 2009;30(8): 1578-86.

56. Hodgkinson GN, Tresco PA, Hlady V. The differential influence of colocalized and segregated dual protein signals on neurite outgrowth on surfaces. Biomaterials. 2007;28: 2590-602.

57. Hoffman LM, Carpenter MK. Characterization and culture of human embryonic stem cells. Nat Biotechnol. 2005; 23(6):699-708.

58. Holmes TC, Delacalle S, Su X, et al. Extensive neurite outgrowth and active synapse formation on self-assembling peptide scaffolds. Proc Natl Acad Sci. 2000;97:6728-33. 
59. Horne MK, Nisbet DR, Forsythe JS, et al. Three-Dimensional Nanofibrous Scaffolds Incorporating Immobilized BDNF Promote Proliferation and Differentiation of Cortical Neural Stem Cells. Stem Cells and Development. 2010;19(6): 843-852.

60. Hou S, Xu Q, Tian W, et al. The repair of brain lesion by implantation of hyaluronic acid hydrogels modified with laminin. J Neurosci Methods. 2005;148(1):60-70.

61. Huang EJ, Reichardt LF. Neurotrophins: roles in neuronal development and function. Annu Rev Neurosci. 2001; 24:677-736.

62. Hubbell JA. Bioactive biomaterials. Curr Opin Biotechnol. 1999;10(2):123-9.

63. Huber AB, Kolodkin AL, Ginty DD, et al. Signaling at the growth cone: ligand-receptor complexes and the control of axon growth and guidance. Ann Rev Neurosci. 2003;26: 509-63.

64. Ilkhanizadeh S, Teixeira AI, Hermanson O. Inkjet printing of macromolecules on hydrogels to steer neural stem cell differentiation. Biomaterials. 2007;28:3936-43.

65. Ishikawa N, Suzuki Y, Ohta M, et al. Peripheral nerve regeneration through the space formed by a chitosan gel sponge. J Biomed Mater Res A. 2007;83A(1):33-40.

66. Itoh S, Suzuki M, Yamaguchi I, et al. Development of a nerve scaffold using a tendon chitosan tube. Artif Organs. 2003;27(12):1079-88.

67. Itoh S, Yamaguchi I, Suzuki M, et al. Hydroxyapatite-coated tendon chitosan tubes with adsorbed laminin peptides facilitate nerve regeneration in vivo. Brain Res. 2003;993(1-2): 111-23.

68. Jiang FX, Yurke B, Firestein BL, et al. Neurite outgrowth on a DNA crosslinked hydrogel with tunable stiffness. Ann Biomed Eng. 2008;36(9):1565-79.

69. Jiang X, Georges PC, Li B, et al. Cell growth in response to mechanical stiffness is affected by neuron-astroglia interactions. Open Neurosci J. 2007;1:7-14.

70. Johnson PW, Abramow-Newerly W, Seilheimer B, et al. Recombinant myelin-associated glycoprotein confers neural adhesion and neurite outgrowth function. Neuron. 1989;3(3): 377-85.

71. Kapur TA, Shoichet MS. Immobilized concentration gradients of nerve growth factor guide neurite outgrowth. J Biomed Mater Res A. 2004;68(2):235-43.

72. Keenan TM, Folch A. Biomolecular gradients in cell culture systems. Lab Chip. 2008;8:34-57.

73. Kim Y-T, Haftel VK, Kumar S, et al. The role of aligned polymer fiber-based constructs in the bridging of long peripheral nerve gaps. Biomaterials. 2008;29:3117-27.

74. Koh HS, Yong T, Chan CK, et al. Enhancement of neurite outgrowth using nano-structured scaffolds coupled with laminin. Biomaterials. 2008;29:3574-82.

75. Kordower JH, Chu Y, Hauser RA, et al. Lewy bodylike pathology in long-term embryonic nigral transplants in Parkinson's disease. Nat Med. 2008;14(5): 504-6.

76. Kordower JH, Rosenstein JM, Collier TJ, et al. Functional fetal nigral grafts in a patient with Parkinson's disease: chemoanatomic, ultrastructural, and metabolic studies. J Comp Neurol. 1996;370:203-30.

77. Le HP. Progress and trends in ink-jet printing technology. J Imaging Sci Technol. 1998;42(1):49-62.
78. Leach JB, Brown XQ, Jacot JG, et al. Neurite outgrowth and branching of PC12 cells on very soft substrates sharply decreases below a threshold of substrate rigidity. J Neural Eng. 2007;4:26-34.

79. Li D, Wang Y, Xia Y. Electrospinning of polymeric and ceramic nanofibers as uniaxially aligned arrays. Nano Lett. 2003;3(8):1167-71.

80. Li J-Y, Englund E, Holton JL, et al. Lewy bodies in grafted neurons in subjects with Parkinson's disease suggest host-to-graft disease propagation. Nat Med. 2008;14(5): 501-3.

81. Lindvall O, Björklund A. Dopaminergic innervation of the globus pallidus by collaterals from the nigrostriatal pathway. Brain Res. 1979;172(1):169-73.

82. Lindvall O, Björklund A. Cell therapy in Parkinson's disease. NeuroRx. 2004;1(4):382-93.

83. Lu P, Tuszynski MH. Growth factors and combinatorial therapies for CNS regeneration. Exp Neurol. 2008;209: 313-20.

84. Luckenbill-Edds L. Laminin and the mechanism of neuronal outgrowth. Brain Res Rev. 1997;23:1-27.

85. Lutolf MP, Hubbell JA. Synthetic biomaterials as instructive extracellular microenvironments for morphogenesis in tissue engineering. Nat Biotechnol. 2005;23(1):47-55.

86. Mahoney MJ, Anseth KS. Three-dimensional growth and function of neural tissue in degradable polyethylene glycol hydrogels. Biomaterials. 2006;27:2265-74.

87. Mahoney MJ, Chen RR, Tan J, et al. The influence of microchannels on neurite growth and architecture. Biomaterials. 2005;26:771-8.

88. Martino G, Pluchino S. The therapeutic potential of neural stem cells. Nat Rev Neurosci. 2006;7(5):395-406.

89. Massia SP, Hubbell JA. An RGD spacing of $440 \mathrm{~nm}$ is sufficient for integrin alpha $\mathrm{V}$ beta 3- mediated fibroblast spreading and $140 \mathrm{~nm}$ for focal contact and stress fiber formation. J Cell Biol. 1991;114(5):1089-100.

90. Mckay R, Kittappa R. Will stem cell biology generate new therapies for Parkinson's disease? Neuron. 2008;58(5): 659-61.

91. Mendez I, Sanchez-Pernaute R, Cooper O, et al. Cell type analysis of functional fetal dopamine cell suspension transplants in the striatum and substantia nigra of patients with Parkinson's disease. Brain. 2005;128(7):1498-510.

92. Mendez I, Vinuela A, Astradsson A, et al. Dopamine neurons implanted into people with Parkinson's disease survive without pathology for 14 years. Nat Med. 2008;14(5): 507-9.

93. Moore K, Macsween M, Shoichet MS. Immobilized concentration gradients of neurotrophic factors guide neurite outgrowth of primary neurons in macroporous scaffolds. Tissue Eng. 2006;12(2):267-78.

94. Myer DJ, Gurkoff GG, Lee SM, et al. Essential protective roles of reactive astrocytes in traumatic brain injury. Brain. 2006;129(10):2761-72.

95. Nadarajah B, Parnavelas JG. Modes of neuronal migration in the developing cerebral cortex. Nat Rev Neurosci. 2002;3(6):423-32.

96. Nakatomi H, Kuriu T, Okabe S, et al. Regeneration of hippocampal pyramidal neurons after ischemic brain injury by recruitment of endogenous neural progenitors. Cell. 2002;110(4):429-41. 
97. Ninkovic J, Götz M. Signaling in adult neurogenesis: from stem cell niche to neuronal networks. Curr Opin Neurobiol. 2007;17(3):338-44.

98. Nisbet DR, Crompton KE, Horne MK, et al. Neural tissue engineering of the CNS using hydrogels. J Biomed Mater Res B Appl Biomater. 2008;87B(1):251-63.

99. Nisbet DR, Forsythe JS, Shen W, et al. Review paper: a review of the cellular response on electrospun nanofibers for tissue engineering. J Biomater Appl. 2008;24:7-29.

100. Nisbet DR, Pattanawong S, Ritchie NE, et al. Interaction of embryonic cortical neurons on nanofibrous scaffolds for neural tissue engineering. J Neural Eng. 2007;4:35-41.

101. Nisbet DR, Rodda AE, Horne MK, et al. Implantation of Functionalized Thermally Gelling Xyloglucan Hydrogel Within the Brain: Associated Neurite Infiltration and Inflammatory Response. Tissue Engineering Part A. 2010; 16:2833-42.

102. Nisbet DR, Rodda AE, Horne MK, et al. Neurite infiltration and cellular response to electrospun polycaprolactone scaffolds implanted into the brain. Biomaterials. 2009; 30(27):4573-80.

103. Nisbet DR, Yu LMY, Zahir T, et al. Characterization of neural stem cells on electrospun poly(caprolactone) submicron scaffolds: evaluating their potential in neural tissue engineering. J Biomater Sci Polymer Ed. 2008;19:623-34.

104. Okamoto T, Suzuki T, Yamamoto N. Microarray fabrication with covalent attachment of DNA using bubble jet technology. Nat Biotechnol. 2000;18:438-41.

105. Olanow CW, Goetz CG, Kordower JH, et al. A doubleblind controlled trial of bilateral fetal nigral transplantation in Parkinson's disease. Ann Neurol. 2003;54(3):403-14.

106. Olanow CW, Kordower JH, Freeman TB. Fetal nigral transplantation as a therapy for Parkinson's disease. Trends Neurosci. 1996;19(3):102-9.

107. Palace J. Neuroprotection and repair. J Neurol Sci. 2008; 265(1-2):21-5.

108. Parish CL, Arenas E. Stem-cell-based strategies for the treatment of Parkinson's disease. Neurodegener Dis. 2007;4:339-47.

109. Park KI, Teng YD, Snyder EY. The injured brain interacts reciprocally with neural stem cells supported by scaffolds to reconstitute lost tissue. Nat Biotechnol. 2002;20(11): 1111-7.

110. Pluchino S, Zanotti L, Brini E, et al. Regeneration and repair in multiple sclerosis: the role of cell transplantation. Neurosci Lett. 2009;456:101-6.

111. Pluchino S, Zanotti L, Deleidi M, et al. Neural stem cells and their use as therapeutic tool in neurological disorders. Brain Res Rev. 2005;48(2):211-9.

112. Powell SK, Kleinman HK. Neuronal laminins and their cellular receptors. Int J Biochem Cell Biol. 1997;29(3): 401-14.

113. Pratt AB, Weber FE, Schmoekel HG, et al. Synthetic extracellular matrices for in situ tissue engineering. Biotechnol Bioeng. 2004;86:27-36.

114. Rangappa N, Romero A, Nelson KD, et al. Laminin-coated poly(l-lactide) filaments induce robust neurite growth while providing directional orientation. J Biomed Mater Res. 2000;51:625-34.

115. Ratner BD. A paradigm shift: biomaterials that heal. Polym Int. 2007;56(10):1183-5.
116. Ratner BD, Bryant SJ. Biomaterials: where we have been and where we are going. Annu Rev Biomed Eng. 2004; 6(1):41-75.

117. Recknor JB, Recknor JC, Sakaguchi DS, et al. Oriented astroglial cell growth on micropatterned polystyrene substrates. Biomaterials. 2004;25(14):2753-67.

118. Recknor JB, Sakaguchi DS, Mallapragada SK. Directed growth and selective differentiation of neural progenitor cells on micropatterned polymer substrates. Biomaterials. 2006;27(22):4098-108.

119. Ringeisen BR, Othon CM, Barron JA, et al. Jet-based methods to printing living cells. Biotechnol J. 2006;1:930-48.

120. Riquelme PA, Drapeau E, Doetsch F. Brain microecologies: neural stem cell niches in the adult mammalian brain. Phil Trans R Soc B. 2008;363:123-37.

121. Roda A, Guardigli M, Russo C, et al. Protein microdeposition using a conventional ink-jet printer. BioTechniques. 2000;28(3):492-6.

122. Roth EA, Xu T, Das M, et al. Inkjet printing for highthroughput cell patterning. Biomaterials. 2004;25:3707-15.

123. Ruiz A, Buzanska L, Ceriotti L, et al. Stem-cell culture on patterned bio-functional surfaces. J Biomater Sci Polym Ed. 2008;19(12):1649-57.

124. Ruiz A, Buzanska L, Gilliland D, et al. Micro-stamped surfaces for the patterned growth of neural stem cells. Biomaterials. 2008;29(36):4766-74.

125. Sanjana NE, Fuller SB. A fast flexible ink-jet printing method for patterning dissociated neurons in culture. J Neurosci Methods. 2004;136(2):151-63.

126. Santiago LY, Nowak RW, Peter RJ, et al. Peptide-surface modification of poly(caprolactone) with laminin-derived sequences for adipose-derived stem cell applications. Biomaterials. 2006;27(15):2962-9.

127. Saunders RE, Gough JE, Derby B. Delivery of human fibroblast cells by piezoelectric drop-on-demand inkjet printing. Biomaterials. 2008;29:193-203.

128. Scadden DT. The stem-cell niche as an entity of action. Nature. 2006;441(7097):1075-9.

129. Schense JC, Bloch J, Aebischer P, et al. Enzymatic incorporation of bioactive peptides into fibrin matrices enhances neurite extension. Nat Biotechnol. 2000;18(4):415-9.

130. Schmidt RH, Björklund A, Stenevi U. Intracerebral grafting of dissociated CNS tissue suspensions: a new approach for neuronal transplantation to deep brain sites. Brain Res. 1981;218(1-2):347-56.

131. Schnell E, Klinkhammer K, Balzer S, et al. Guidance of glial cell migration and axonal growth on electrospun nanofibers of poly-e-caprolactone blend. Biomaterials. 2007;28:3012-25.

132. Silva GA, Czeisler C, Niece K, et al. Selective differentiation of neural progenitor cells by high-epitope density nanofibers. Science. 2004;303:1352-5.

133. Simonet M, Schneider OD, Neuenschwander P, et al. Ultraporous 3D polymer meshes by low-temperature electrospinning: Use of ice crystals as a removable void template. Polym Eng Sci. 2007;47(12):2020-6.

134. Sofroniew MV. Reactive astrocytes in neural repair and protection. Neuroscientist. 2005;11(5):400-7.

135. Sofroniew MV, Howe CL, Mobley WC. Nerve growth factor signaling, neuroprotection, and neural repair. Annu Rev Neurosci. 2001;24:1217-81. 
136. Song H, Poo M-M. The cell biology of neuronal navigation. Nat Cell Biol. 2001;3:E81-8.

137. Sonntag K-C, Simantov R, Isacson O. Stem cells may reshape the prospect of Parkinson's disease therapy. Mol Brain Res. 2005;134(1):34-51.

138. Stein DG, Hoffman SW. Concepts of CNS plasticity in the context of brain damage and repair. J Head Trauma Rehabil. $2003 ; 18(4): 317$

139. Stephens B, Mueller AJ, Shering AF, et al. Evidence of a breakdown of corticostriatal connections in Parkinson's disease. Neuroscience. 2005;132(3):741-54.

140. Streit W, Mrak R, Griffin WS. Microglia and neuroinflammation: a pathological perspective. J Neuroinflammation. 2004;1(1): 14 .

141. Studer L, Tabar V, Mckay RDG. Transplantation of expanded mesencephalic precursors leads to recovery in parkinsonian rats. Nat Neurosci. 1998;1(4):290-5.

142. Teo WE, Ramakrishna S. A review on electrospinning design and nanofibre assemblies. Nanotechnology. 2006;17: 89-106.

143. Tessier-Lavigne M, Placzek M. Target attraction - are developing axons guided by chemotropism? Trends Neurosci. 1991;14:303-10.

144. Thompson DM, Buettner HM. Schwann cell response to micropatterned laminin surfaces. Tissue Eng. 2001;7(3): 247-65.

145. Tian WM, Hou SP, Ma J, et al. Hyaluronic acid-poly-Dlysine-based three-dimensional hydrogel for traumatic brain injury. Tissue Eng. 2005;11(3/4):513-25.

146. Tomihata K, Ikada Y. In vitro and in vivo degradation of films of chitin and its deacetylated derivatives. Biomaterials. 1997;18(7):567-75.

147. Tong YW, Shoichet MS. Enhancing the neuronal interaction on fluoropolymer surfaces with mixed peptides or spacer group linkers. Biomaterials. 2001;22(10):1029-34.

148. Toulouse A, Sullivan AM. Progress in Parkinson's diseasewhere do we stand? Prog Neurobiol. 2008;85(4):376-92.

149. Tysseling-Mattiace VM, Sahni V, Niece KL, et al. Selfassembling nanofibers inhibit glial scar formation and promote axon elongation after spinal cord injury. J Neurosci. 2008;28(14):3814-23.

150. Van Praag H, Schinder AF, Christie BR, et al. Functional neurogenesis in the adult hippocampus. Nature. 2002; 415(6875):1030-4.
151. Vappou J, Breton E, Choquet P, et al. Assessment of in vivo and post-mortem mechanical behavior of brain tissue using magnetic resonance elastography. J Biomech. 2008;41(14): 2954-9.

152. West JL, Hubbell JA. Polymeric biomaterials with degradation sites for proteases involved in cell migration. Macromolecules. 1999;32(1):241-4.

153. Willits RK, Skornia SL. Effect of collagen gel stiffness on neurite extension. J Biomater Sci Polym Ed. 2004; 15(12):1521-31.

154. Winkler C, Kirik D, Björklund A. Cell transplantation in Parkinson's disease: how can we make it work? Trends Neurosci. 2005;28(2):86-92.

155. Woerly S, Petrov P, Sykova E, et al. Neural tissue formation within porous hydrogels implanted in brain and spinal cord lesions: ultrastructural, immunohistochemical, and diffusion studies. Tissue Eng. 1999;5(5):467-88.

156. Xie J, Willerth SM, Li X, et al. The differentiation of embryonic stem cells seeded on electrospun nanofibers into neural lineages. Biomaterials. 2009;30(3):354-62.

157. Xu T, Gregory CA, Molnar P, et al. Viability and electrophysiology of neural cell structures generated by the inkjet printing method. Biomaterials. 2006;27:3580-8.

158. Xu T, Jin J, Gregory C, et al. Inkjet printing of viable mammalian cells. Biomaterials. 2005;26:93-9.

159. Yang F, Murugan R, Ramakrishna S, et al. Fabrication of nano-structured porous PLLA scaffold intended for nerve tissue engineering. Biomaterials. 2004;25(10):1891-900.

160. Yang F, Murugan R, Wang S, et al. Electrospinning of nano/ micro scale poly(L-lactic acid) aligned fibers and their potential in neural tissue engineering. Biomaterials. 2005; 26:2603-10.

161. Yiu G, He Z. Glial inhibition of CNS axon regeneration. Nat Rev Neurosci. 2006;7(8):617-27.

162. Yu LMY, Wosnick JH, Shoichet MS. Miniaturized system of neurotrophin patterning for guided regeneration. J Neurosci Methods. 2008;171:253-63.

163. Zhang S. Fabrication of novel biomaterials through molecular self-assembly. Nat Biotechnol. 2003;21(10):1171-8.

164. Zhang Z, Yoo R, Wells M, et al. Neurite outgrowth on wellcharacterized surfaces: preparation and characterization of chemically and spatially controlled fibronectin and RGD substrates with good bioactivity. Biomaterials. 2005;26: 47-61. 